\title{
Functional melanoma cell heterogeneity is regulated by MITF-dependent cell-matrix interactions
}

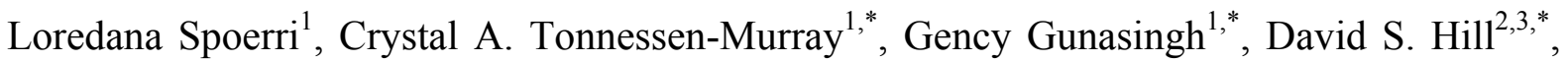
Kimberley A. Beaumont ${ }^{2,3, *}$, Russell J. Jurek ${ }^{4}$, Gilles C. Vanwalleghem ${ }^{5}$, Mitchell E. Fane ${ }^{1}$, Sheena M. Daignault ${ }^{1}$, Nicholas Matigian ${ }^{1,6}$, Ethan K. Scott ${ }^{5}$, Aaron G. Smith ${ }^{7}$, Samantha J. Stehbens $^{1}$, Helmut Schaider ${ }^{1, \#}$, Wolfgang Weninger ${ }^{2,3, \#}$, Brian Gabrielli, ${ }^{8, \#}$, Nikolas K. Haass $^{1,2,3}$

${ }^{1}$ The University of Queensland Diamantina Institute, The University of Queensland, Brisbane, QLD, Australia; ${ }^{2}$ The Centenary Institute, The University of Sydney, Newtown, NSW, Australia; ${ }^{3}$ Discipline of Dermatology, Sydney Medical School, The University of Sydney, Camperdown, NSW, Australia; ${ }^{4}$ CSIRO Astronomy \& Space Sciences, Australia Telescope National Facility, Epping, NSW, Australia; ${ }^{5}$ School of Biomedical Sciences, The University of Queensland, Brisbane, QLD, Australia; ${ }^{6} \mathrm{QFAB}$ Bioinformatics, Institute for Molecular Bioscience, University of Queensland, Brisbane, Queensland, Australia. ${ }^{7}$ Queensland University of Technology, Brisbane, Australia; ${ }^{8}$ Mater Research Institute, The University of Queensland, Brisbane, QLD, Australia

*/\# These authors contributed equally to this work

\section{Correspondence:}

Nikolas K. Haass, The University of Queensland Diamantina Institute, Translational Research Institute, 37 Kent St, Woolloongabba, QLD 4102, Australia. Phone +61 73443 7087; fax +61 73443 6966; e-mail: n.haass1@uq.edu.au 


\section{Summary}

Phenotypic and functional cancer cell heterogeneity limits the efficacy of targeted and immuno-therapies. The transcription factor MITF is known to regulate melanoma cell plasticity and, consequently, response to drugs. However, the underlying mechanisms of this phenomenon remain incompletely understood. Here, we show that MITF levels control functional melanoma cell heterogeneity by fine-tuning the ability to contract the extracellular matrix, the maturation of focal adhesions and ROCK-mediated melanoma cell contractility. Modulation of MITF expression alters extracellular matrix organization, melanoma cell morphology and solid stress in three-dimensional melanoma spheroids, thereby accounting for spatial differences in cell cycle dynamics. Together, our data identify MITF as a master regulator of the melanoma micro-architecture and point towards novel targeting strategies for cancer cell heterogeneity.

Significance. Development of drug resistance is a major cause of melanoma therapy failure. The role of MITF in melanoma response to therapy has been discussed controversially, which can be explained, at least in part, through the rheostat model linking MITF activity to cell proliferation. Heterogeneity is widely associated with therapy resistance, however, whether cell phenotype switching, mediated by MITF, is responsible for treatment resistance is not known. Our findings provide an in-depth mechanistic understanding of the MITF-mediated regulation of cell cycle behavior and physical regulation of the tumor architecture. As MITF is not amenable to direct drug targeting, the identification of mediators of MITF-triggered functional heterogeneity reveals novel targets that can be deployed to control this phenomenon.

Key words. MITF, melanoma, phenotypic heterogeneity, plasticity, proliferation, $\mathrm{G}_{1}$-arrest, ECM, mechanotransduction, solid stress, contractility, Rho-ROCK-myosin signaling pathway 


\section{Introduction}

Despite the unprecedented success of MAPK pathway and immune checkpoint inhibitors, many patients with advanced melanoma still die due to therapy resistance (Bai et al., 2019). Melanoma is amongst the most heterogeneous cancers at inter-patient, inter-tumor and intratumor level (Grzywa et al., 2017). Tumor heterogeneity limits effectiveness of targeted cancer therapies and promotes drug resistance (Ahmed and Haass, 2018).

One of the key factors implicated in the regulation of melanoma cell proliferation and invasion is microphthalmia-associated transcription factor (MITF), a master regulator of melanocyte biology regulating melanocyte survival, proliferation and melanogenic protein expression (Levy et al., 2006; Tsao et al., 2012). MITF is expressed in 56\% of human primary melanomas and $23 \%$ of melanoma metastases (Nazarian et al., 2010). Together with mutant BRAF, amplified MITF can act as an oncogene (Garraway et al., 2005). Additionally, a recurrent mutation in MITF (E318K) was found that predisposes to familial and sporadic melanoma (Bertolotto et al., 2011; Yokoyama et al., 2011). MITF has been shown to both enhance and inhibit melanoma proliferation. These conflicting functions can be explained by the rheostat model, which states that very high levels of MITF predispose melanoma cells to cell cycle arrest and differentiation, by controlling cell cycle regulators, whereas critically low MITF levels lead to cell cycle arrest and apoptosis; only intermediate levels favor proliferation (Carreira et al., 2005; Du et al., 2004; Gray-Schopfer et al., 2007; Loercher et al., 2005). Two distinct gene expression signatures in melanoma are characterized by MITF levels: intermediate-high MITF (from now referred to as MITF ${ }^{\text {high }}$ ) 'proliferative phenotype' and intermediate-low MITF (from now referred to as MITF ${ }^{\text {low }}$ ) ‘invasive phenotype' (Hoek et al., 2006), which were shown to oscillate in vivo (Hoek et al., 2008a). These findings demonstrate that MITF is closely tied with melanoma progression, but its precise role remains unclear. 
MITF expression has been associated with therapy response in numerous reports, however the mechanism involved remains confounding with both beneficial and detrimental effects identified (Arozarena and Wellbrock, 2017). The MITF rheostat model is likely to be central to divergent responses to MAPK pathway inhibition, with intermediate MITF expression serving as a marker for treatment response while very low or very high MITF levels conferring resistance. In this context, it is plausible to attribute the underlying efficacy of drug response to MITF-mediated regulation of the cell cycle. In fact, $\mathrm{G}_{1}$-arrested and dormant cells are more prone than cycling cells to develop drug tolerance and resistance (Beaumont et al., 2016; Haass and Gabrielli, 2017; Ravindran Menon et al., 2015), while excessive proliferation may counteract drug-mediated cell killing, ultimately hindering drug efficacy. Intermediate levels of MITF activity may provide an effective therapeutic window with a balance in proliferation and $\mathrm{G}_{1}$-arrest in between the two extreme scenarios (Ahmed and Haass, 2018).

In addition to genetic and epigenetic factors, the microenvironment plays a pivotal role in determining the cycling state of a cell. Beyond well-known determinants of proliferation and quiescence such as nutrients, growth factors and mitogens, another factor has been largely implicated in regulating cell proliferation, both in normal tissue and in cancer: the extracellular matrix (ECM) (Fiore et al., 2018; Pickup et al., 2014). With its multitude of biochemical and biomechanical properties, the ECM not only acts as a scaffold to determine tissue morphology and physical characteristics, but also influences signaling and biology of the cells it surrounds (Jansen et al., 2017; Ju et al., 2018). Integrin-based cell-matrix adhesions are crucial mediators of biochemical and mechanical cues between the ECM and cells, as they transmit information of the composition as well as the rigidity of the ECM (Guo and Giancotti, 2004). This subsequently triggers a multitude of signaling cascades that result in adaptive responses affecting proliferation, morphology, motility and many other cellular properties. Insight into the interplay between MITF and the ECM is limited, and what is known is mainly in the context 
of metalloproteinases and matrix degradation (Bianchi-Smiraglia et al., 2017; Hoek et al., 2008b). A recent study on the effects of the tumor microenvironment on MITF expression demonstrated that a stiffer matrix leads to increased MITF mRNA levels in melanoma cell lines (Miskolczi et al., 2018). Another study identified a correlation between progressive loss of extracellular matrix genes and an MITF gene downregulation during tumor progression, which was modelled through pseudotime dynamics analysis of melanoma single-cell transcriptomes (Loeffler-Wirth et al., 2018). Yet, to the best of our knowledge, there is no study that reports MITF-mediated regulation of the ECM.

Using real-time cell cycle imaging, we have previously demonstrated that melanoma spheroids and xenografts are composed of differentially cycling tumor cells in a subcompartment-specific distribution, i.e. areas of proliferating and areas of $\mathrm{G}_{1}$-arrested cells (Haass et al., 2014). We also showed a spatiotemporal and functional correlation between $\mathrm{G}_{1}$-arrest and oxygen/nutrient deprivation, which can switch in response to microenvironmental cues (Haass et al., 2014) and coined the term dynamic phenotypic heterogeneity (Haass, 2015). Now we demonstrate that this heterogeneity is consistently decreased in vivo and in vitro by high expression of MITF. This phenomenon is not associated with cell cycle profile changes in adherent culture, suggesting that MITF mediates these effects through factors requiring a 3D environment, rather than simply through its rheostat-based influence on proliferation. Decreased $\mathrm{G}_{1}$-arrest does not correlate with reduced hypoxia, indicating that high MITF expression allows a portion of hypoxic cells to sustain cell cycle despite oxygen deprivation. Analogously, modulation of MITF expression leads to changes of spheroid architecture, solid stress and ECM organization. Furthermore, MITF-overexpressing cells exhibit a decrease in cell-ECM adhesion, in myosin phosphorylation and in the ability to contract the surrounding ECM. Inhibition of the Rho/ROCK signaling pathway mimics the effects of high MITF expression on spheroid 
morphology, solid stress and heterogeneous cell cycling. In summary, we show that MITF mediates functional heterogeneity by affecting the cell-ECM crosstalk in melanoma.

\section{Results}

\section{Phenotypic heterogeneity in melanoma xenograft tumors in vivo is dependent on expression levels of MITF}

We investigated the influence of MITF on phenotypic heterogeneity, i.e. the intratumoral distribution of differentially cycling melanoma cells in vivo, using melanoma cell lines transduced with the fluorescent ubiquitination-based cell cycle indicator (FUCCI) system (Haass et al., 2014; Sakaue-Sawano et al., 2008). To allow for better visibility for colordeficient readers, monomeric Kusabira Orange2 (mKO2; G1 phase) and monomeric Azami Green (mAG; S/G2/M) fluorescence will be shown in magenta and green, respectively. Endogenously MITF $^{\text {low }}\left(1205 \mathrm{Lu}\right.$ and C8161) and MITF $^{\text {high }}$ (WM983C, WM164, 451Lu) FUCCI-transduced melanoma cell lines (Fig. 1A) were xenografted subcutaneously into NOD/SCID mice. MITF and its transcriptional target RAB27A (Chiaverini et al., 2008) exhibited a similar expression pattern, indicating that MITF was functional in the MITF ${ }^{\text {high }}$ cell lines (Fig. 1A).

Analysis of histologic sections of these tumors by confocal microscopy revealed two distinct cohorts based on distribution of differentially cycling cells (Fig. 1B, S1A). The MITF ${ }^{\text {high }}$ cohort exhibited a predominantly homogenous distribution of cells positive for $\mathrm{mKO} 2$ and $\mathrm{mAG}$, indicating proliferation throughout. In contrast, the $\mathrm{MITF}^{\text {low }}$ cohort showed sharply demarcated proliferating and $\mathrm{G}_{1}$-arrested clusters, predominantly composed of $\mathrm{mKO} 2^{+}$cells (Fig. 1B, S1A).

To objectively analyze the distribution of proliferating cells within these xenografts, we adapted an astrophysical correlation function that has been used to describe the clustering of 
A
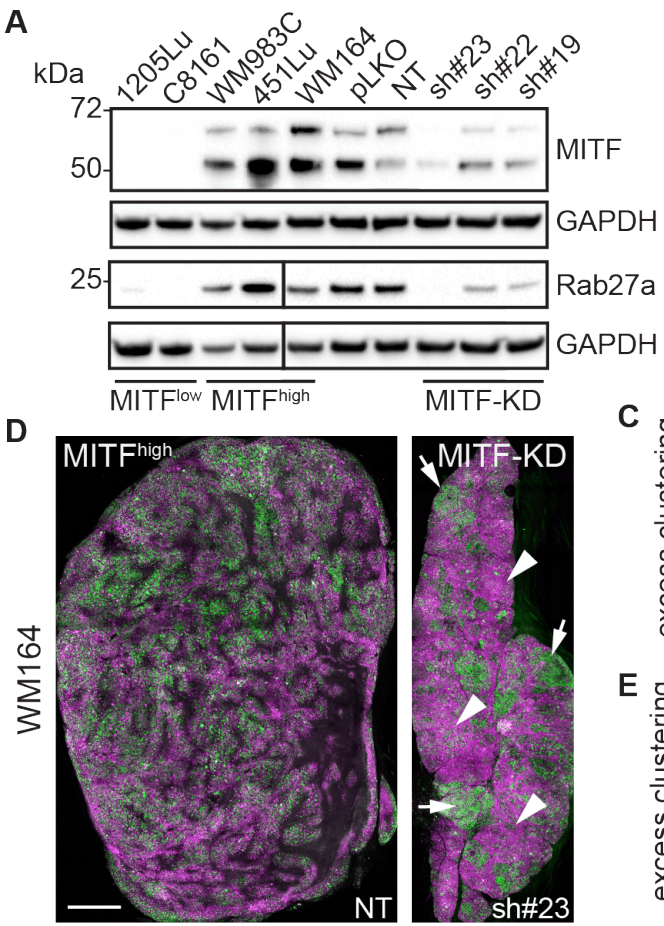

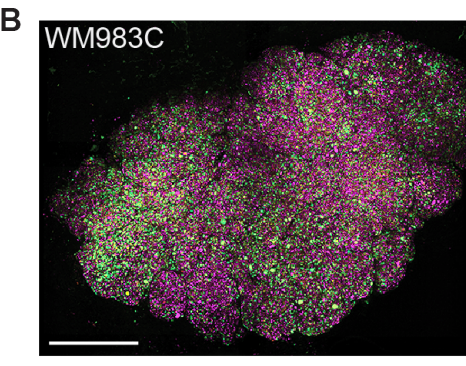

MITFhigh
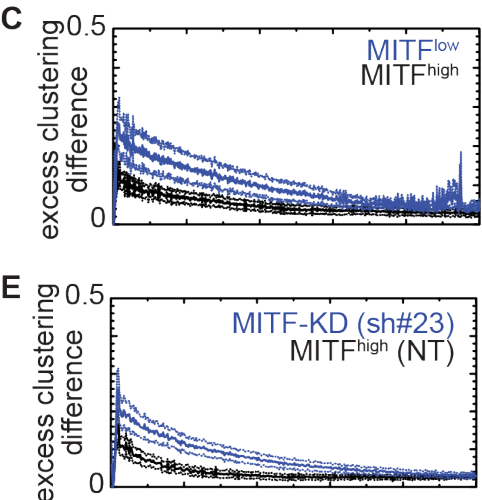

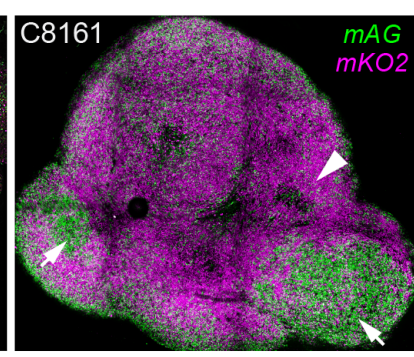

MITFlow
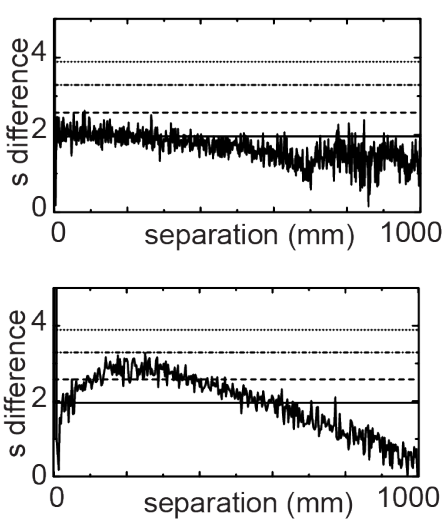

Figure 1: Phenotypic heterogeneity in melanoma xenograft tumors in vivo is dependent on expression levels of MITF. (A) Protein levels of MITF and its downstream effector RAB27A in the melanoma cell lines used for engrafting. Immunoblots are representative of three independent experiments. The vertical line indicates an unrelated excised lane from the original blot. (B,D) Representative examples of predominantly homogeneously proliferating MITF $^{\text {high }}($ WM983C (B) and WM164-NT (D)) and clustered MITF low (C8161 (B) and WM164sh\#23 (D)) xenografts. Arrows and arrowheads indicate proliferating and $G_{1}$-arrested clusters, respectively; scale bars: $1 \mathrm{~mm} .(\boldsymbol{C}, \boldsymbol{E})$ Quantitative analysis of the differences in $\mathrm{mKO}^{+}$ (magenta) and $\mathrm{mAG}^{+}$(green) cell clustering in the two cohorts. Clustering of $\mathrm{mKO}^{+}$and $m A G^{+}$cells was first compared to a random distribution, then the absolute clustering differences were obtained for each tumor image. Error bars represent \pm SEM of at least 19 (C) or 14 (E) tumors per cohort. In the sigma difference (s difference) plots, solid, dashed, dotdash and dotted horizontal lines correspond to p-values of 0.05, 0.01, 0.001, 0.0001. NT, nontargeting shRNA, mKO2, monomeric Kusabira Orange2, magenta; mAG, monomeric Azami Green, green; KD, knock-down. 
galaxies (Landy and Szalay, 1993). We measured the number of $\mathrm{mKO}^{+}$or $\mathrm{mAG}^{+}$cell pairs at a given separation and compared that to the number of pairs we would expect if the cells were randomly distributed. To identify clustering differences irrespective of which cells $\left(\mathrm{mKO} 2^{+}\right.$or $\mathrm{mAG}^{+}$) were more strongly clustered, we plotted the absolute difference in the $\mathrm{mKO}^{+}$and $\mathrm{mAG}^{+}$cell clustering (Fig. S1B-E). This analysis confirmed that the MITF ${ }^{\text {low }}$ cohort had significantly greater clustering compared to the MITF $^{\text {high }}$ cohort (Fig. 1C).

To assess the functional role of MITF in intratumoral phenotypic heterogeneity, we depleted MITF in endogenously MITF $^{\text {high }}$ FUCCI-WM164 melanoma cells using shRNA-expressing lentiviral particles (MITF-KD) and generated xenografts. Downregulation of MITF protein levels by approximately $80 \%$ (Fig. 1A; S1F) did not affect the cell cycle profile in 2D culture (Fig. S1H).

While xenografts expressing non-targeting shRNA (NT) controls showed a more homogeneous cell cycle pattern, MITF-depleted xenografts displayed proliferating and $\mathrm{G}_{1}$-arrested cell clusters (Fig. 1D, S1G). Quantitative clustering analysis confirmed a significant difference between $\mathrm{mKO}^{+}$and $\mathrm{mAG}^{+}$cell clustering in $\mathrm{MITF}^{\text {high/shRNA }}$ xenografts compared to $\mathrm{MITF}^{\text {high/NT }}$ controls (Fig. 1E). We thus conclude that the distribution of proliferating cells in melanoma xenografts is linked to MITF levels. We considered the presence of $\mathrm{G}_{1}$-arrested clusters a type of plastic, and potentially reversible, intratumoral heterogeneity. Considering the high variability of MITF levels across melanomas and its recognized link to variable therapy outcome, we decided to investigate the etiology of this phenomenon in an effort to better understand and potentially control it. 


\section{Phenotypic heterogeneity in melanoma spheroids in vitro is dependent on expression levels of MITF}

To elucidate the mechanism underlying MITF-mediated phenotypic heterogeneity, we next utilized a 3D FUCCI melanoma spheroid model. Melanoma spheroids recapitulate the cell cycle behavior in relation to oxygen and nutrient availability observed in xenografts (Haass et al., 2014; Spoerri et al., 2017), except that these are supplied by diffusion and not through vasculature, resulting in a uniform and concentric oxygen and nutrient gradient (Beaumont et al., 2013). This leads to proliferation in the spheroid periphery, $\mathrm{G}_{1}$-arrest in the center and, in some cases, a necrotic core (Haass et al., 2014); the width of these zones is cell line-specific. In agreement with our in vivo findings, we observed that endogenously MITF $^{\text {low }}$ spheroids $\left(\mathrm{C} 8161^{\mathrm{EV}}\right.$ and $\mathrm{WM} 793 \mathrm{~B}^{\mathrm{EV}}$, Fig. 2C and S2C) exhibited an increased area of $\mathrm{G}_{1}$-arrested cells compared to endogenously $\mathrm{MITF}^{\text {high }}$ spheroids (WM164 ${ }^{\mathrm{EV}}$ and $\mathrm{WM} 983 \mathrm{~B}^{\mathrm{EV}}$; Fig. 2A, S2A). As melanoma cells are known to have a high mutation rate, we proceeded to use isogenic cell lines to assess the mechanistic relationship of MITF expression and cell cycle distribution. We depleted MITF in an additional MITF $^{\text {high }}$ melanoma cell line (WM983B) (Fig. S2B) and overexpressed MITF in two endogenously MITF $^{\text {low }}$ melanoma cell lines (C8161 and WM793B) (Fig. 2D; S2D). We then analyzed the spatial distribution of $\mathrm{mKO}^{+}$and $\mathrm{mAG}^{+}$cells in spheroids using confocal microscopy. Because of the relatively uniform and concentric gradient of cell cycle activity, we measured $\% \mathrm{mKO}^{+}\left(\mathrm{mKO}^{+} /\left(\mathrm{mKO}^{+}+\mathrm{mAG}^{+}\right)\right)$cells in relation to the distance from the spheroid surface.

Both empty vector control (EV) and MITF-KD spheroids displayed an external ring of proliferating cells and a $\mathrm{G}_{1}$-arrested center. However, the quiescent center significantly extended to almost reaching the surface of the MITF-KD spheroids (Fig. 2A; S2A). We confirmed this difference by calculating the $\mathrm{mKO} 2^{+}$cell percentage, which showed a steeper increase in MITF-KD spheroids when plotted as a function of distance from the surface (Fig. 

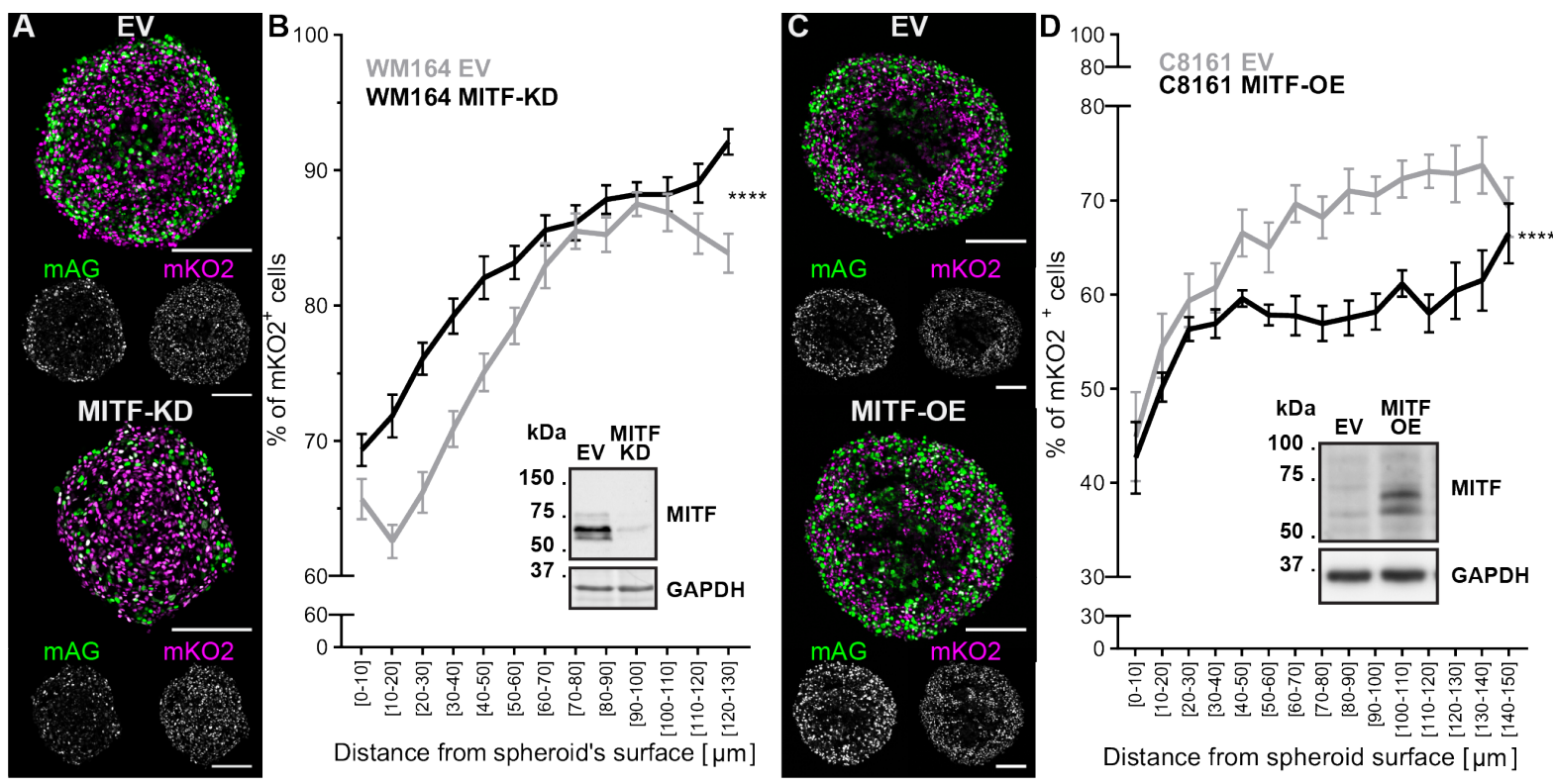

Figure 2: Phenotypic heterogeneity in melanoma spheroids in vitro is dependent on expression levels of MITF. $(A, C)$ Representative FUCCI fluorescence images (monomeric Azami green, mAG, green; monomeric Kusabira Orange2, mKO2, magenta) of equatorial cryosections of spheroids with MITF depleted (WM164 ${ }^{\text {MITF-KD }) \text { or overexpressed (C8161 }} 1^{\text {MITF- }}$ $\left.{ }^{O E}\right)$, and the respective controls (WM164 ${ }^{E V}$ and $\left.C 8161^{E V}\right)$. Areas of $\mathrm{mAG}^{+}$and $\mathrm{mKO2} 2^{+}$cells proliferate, while zones enriched with $\mathrm{mKO}^{+}$cells are $G_{1}$-arrested; scale bars: $200 \mu \mathrm{m} .(\boldsymbol{B}, \boldsymbol{D})$ Analysis of $G_{1}$-arrest spatial distribution. Graphs show the percentage of $\mathrm{mKO}^{+}$cells $\left(\mathrm{mKO}^{+} /\left(\mathrm{mKO}^{+}+\mathrm{mAG}^{+}\right)\right)$as a function of distance from the spheroid surface. Note, cells beyond specific spheroid depths (cell-line dependent) were omitted from the analysis because of high variability driven by core necrosis. WM164: $n=16$ (EV), $n=16$ (MITF-KD); C8161: $n=11$ (EV), $n=12$ (MITF-OE); data: mean \pm SEM; analysis: two-way ANOVA for the effect of MITF on \% of $m \mathrm{KO}^{+}$cells; **** $p<0.0001$. Immunoblots show the level of MITF knockdown (B) and overexpression (D). EV, empty vector; $K D$, knock-down; OE, overexpression.

2C,D; S2C,D). Similar to MITF depletion, MITF overexpression had little or no effect on the cell cycle profile in 2D culture (Fig. S1F). Taken together, these data support an inverse relation between MITF expression and the extent of $\mathrm{G}_{1}$-arrested zones in vivo and in vitro (Fig. $2 \mathrm{~B}$; 
S2B). In line with our xenograft observations, lower MITF levels resulted in an increased area of $\mathrm{G}_{1}$-arrested cells.

\section{High MITF levels allow proliferation of melanoma cells in hypoxia}

As areas of $\mathrm{G}_{1}$-arrest in xenografts and spheroids generally localize with oxygen-deprived zones (Haass et al., 2014), we sought to examine whether the MITF-induced change in $\mathrm{G}_{1^{-}}$ arrest distribution in spheroids correlated with hypoxia. We used pimonidazole staining of spheroid cryosections to assess the degree and location of hypoxia.

Spheroids generated from both endogenously MITF $^{\text {low }}$ and MITF-OE cells had an intense pimonidazole signal located at their core (Fig. 3A; S3A). Quantitation of the percentage of pimonidazole-positive cells relative to location showed a comparable increase from approximately $50 \mu \mathrm{m}$ from the spheroid surface in $\mathrm{C} 8161^{\mathrm{EV}}$ and $\mathrm{C} 8161^{\mathrm{MITF}-\mathrm{OE}}$ spheroids (Fig. 3B). This coincided with the divergence of the $\mathrm{mKO}^{+}$cell percentage curves that we had observed between these two cohorts (Fig. 2D, shaded gray in Fig. 3B). Similarly, in WM793B spheroids, in spite of a higher degree of hypoxia, WM793B ${ }^{\text {MITF-OE }}$ cells sustained cycling at a deeper location compared to WM793B ${ }^{\mathrm{EV}}$ spheroids (Fig. S3A,B). Analogously, the profound $\mathrm{G}_{1}$-arrest in WM164 ${ }^{\mathrm{MITF}-\mathrm{KD}}$ spheroids was matched with a lower degree of hypoxia compared to the less arrested WM164 ${ }^{\mathrm{EV}}$ spheroids (Fig. 3C,D). Moreover, we calculated the percentage of proliferating cells $\left(\mathrm{mAG}^{+}\right)$within the hypoxic zone $\left(\mathrm{pim}^{+}\right)$. This percentage was higher in spheroids generated from MITF ${ }^{\text {high }}$ cells $\left(\mathrm{WM} 164^{\mathrm{EV}}, \mathrm{C} 8161^{\mathrm{MITF}-\mathrm{OE}}, \mathrm{WM} 793^{\mathrm{MITF}-\mathrm{OE}}\right)$ compared to the corresponding MITF ${ }^{\text {low }}$ cells (WM164 ${ }^{\text {MITF-KD }}, \mathrm{C} 8161^{\mathrm{EV}}, \mathrm{WM} 793^{\mathrm{EV}}$ ) (Fig. 3E-H; S3C,D). Altogether these data showed that firstly, the $\mathrm{G}_{1}$-arrest variations driven by changes in MITF expression are unlikely due to changes in microenvironment availability of oxygen and secondly, that MITF protects melanoma cells from cell cycle arrest induced by hypoxia, rather than changing spatial oxygen availability. 

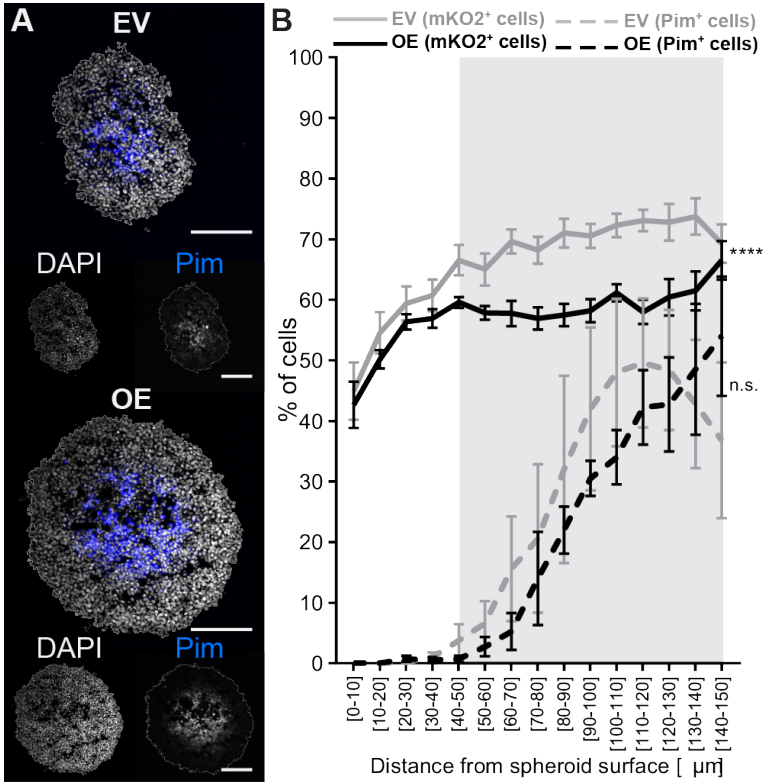

E

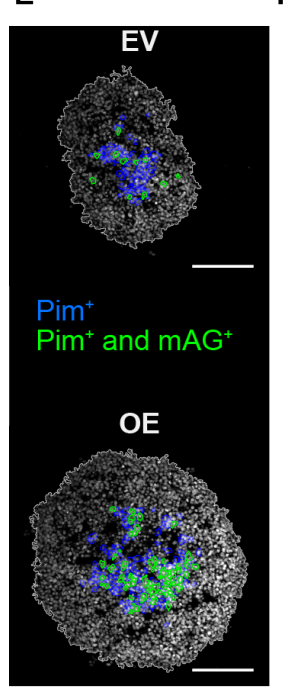

$F$ EV
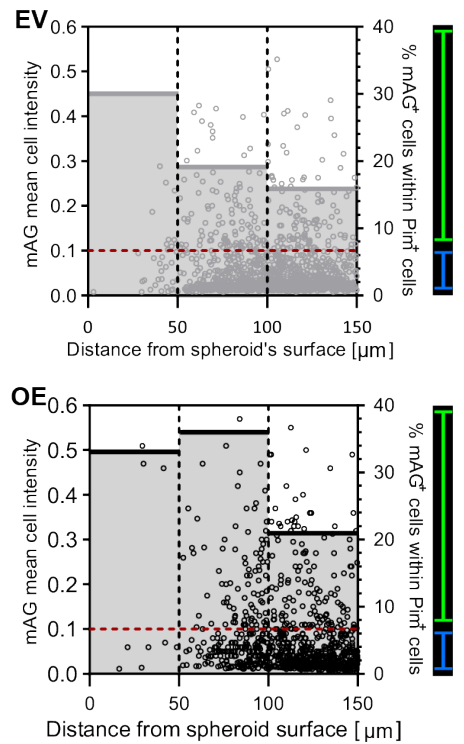
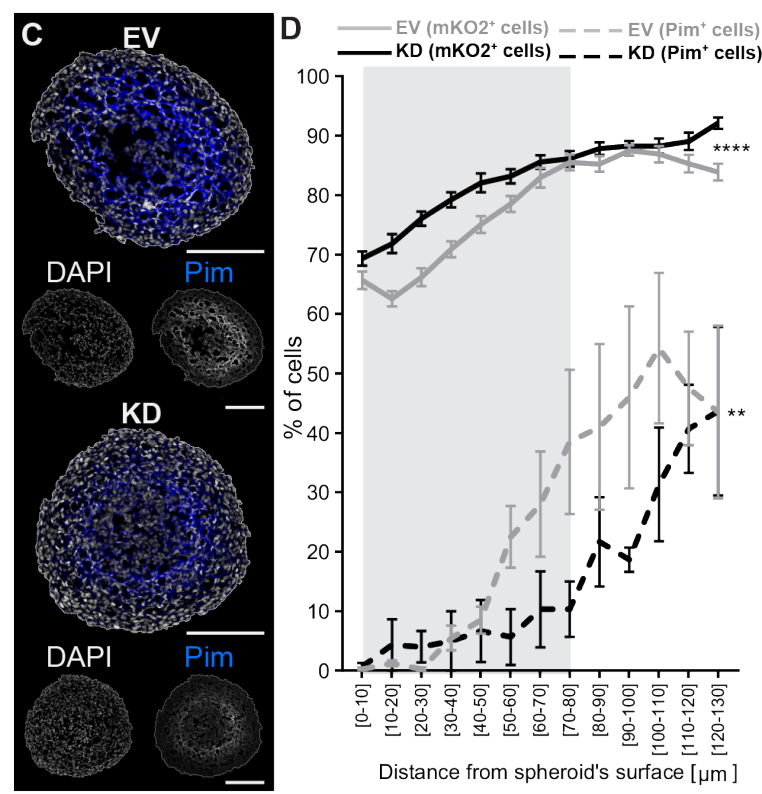

G

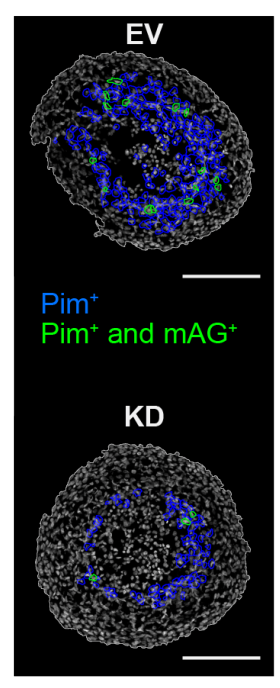

$\mathrm{H}$ EV
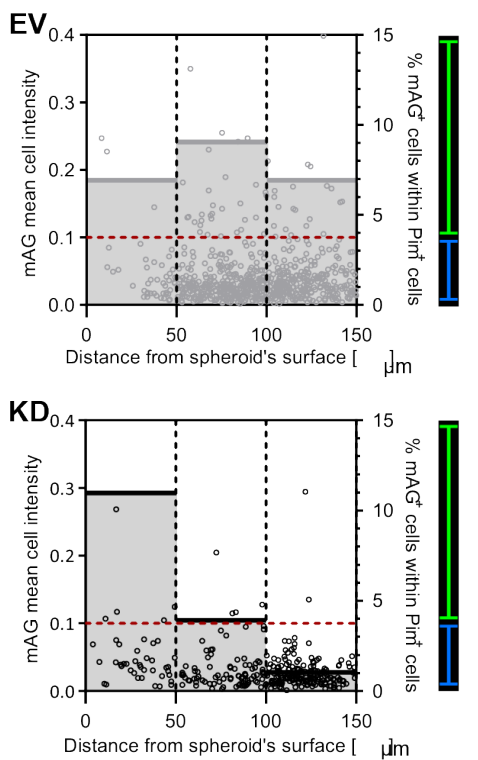

Figure 3: High MITF levels allow proliferation of melanoma cells in hypoxia. (A and C)

Representative fluorescence (DAPI and pimonidazole) images of equatorial cryosections of $C 8161^{E V}$ and $C 8161^{M I T F-O E}$ (A) and WM164 ${ }^{E V}$ and WM164 ${ }^{M I T F-K D}$ (C) spheroids; scale bars: $200 \mu m$. (B and D) Analysis of spatial distribution of hypoxic cells (pimonidazole-positive, Pim $^{+}$) within C8161 (B) and WM164 (D) spheroids. Graphs show the percentage of Pim ${ }^{+}$cells as a function of radial distance from the spheroid surface (dashed curves). Gray shading, distance range from spheroid surface where percentage of the $\mathrm{mKO}^{+}$cells diverges between EV and MITF-OE/KD cohorts, based on data shown in Fig. $2 B$ and $2 D$ (solid curves); $n=5$ 
$\left(C 8161^{E V}\right), n=4\left(C 8161^{\text {MITF-OE }}\right), n=4\left(W M 164^{E V}\right), n=3\left(\right.$ WM164 $\left.4^{M I T F-K D}\right) ;$ data: mean $\pm S E M$; two-way ANOVA analysis for the effect of MITF on \% of Pim ${ }^{+}$cells; $n . s . p>0.05, * * p<0.01$. (E and $\boldsymbol{G})$ CellProfiler generated mask overlaid on DAPI image, showing Pim ${ }^{+}$cells outline (blue) and $\operatorname{Pim}^{+} / m A G^{+}$(green). (F and $\left.\boldsymbol{H}\right)$ Dot plot of $m A G$ mean fluorescence intensity (read on left y axis) of each Pim $^{+}$cell of all analyzed spheroids as a function of distance from the spheroid surface. Grey shaded bars, percentage of $\mathrm{mAG}^{+}$cells within the Pim ${ }^{+}$population (hypoxic and cycling) in each distance bin (read on right y axis). Horizontal red dotted line, threshold for $m A G$ positivity.

\section{MITF overexpression decreases structural integrity and solid stress in melanoma}

\section{spheroids.}

We noted that alteration of MITF levels not only affected cell cycle behavior but also spheroid morphology. MITF-OE melanoma spheroids appeared consistently larger than control spheroids (EV), while MITF-KD spheroids appeared slightly reduced in size (Figs. 2, S2, 3, S3). These observations were confirmed by bright field microscopy measurement of spheroid projected areas and diameter (Fig. S4A). Spheroids have distinct equatorial (x/y dimensions) and polar diameters ( $\mathrm{z}$ dimension) and tend to rest on their larger surface in liquid. To assess the polar diameter, we imaged spheroids using single plane illumination microscopy (SPIM). Consistent with our bright field microscopy observations, we revealed that MITF-OE spheroids had an increased equatorial diameter, but surprisingly a smaller polar diameter (Fig. 4A; S4B), resulting in a similar spheroid volume between the two cohorts of most cell lines assessed (Fig. S4C). We interpret this finding as a redistribution of the same mass into a more oblate (flatter) spheroid, as supported by the consistently decreased roundness (equatorial to polar diameter ratios, Fig. 4C). In contrast, MITF-KD had no effect on roundness (Fig. 4C) but decreased the volume (Fig. S4C). The former is likely due to the fact that a spheroid that is already round 

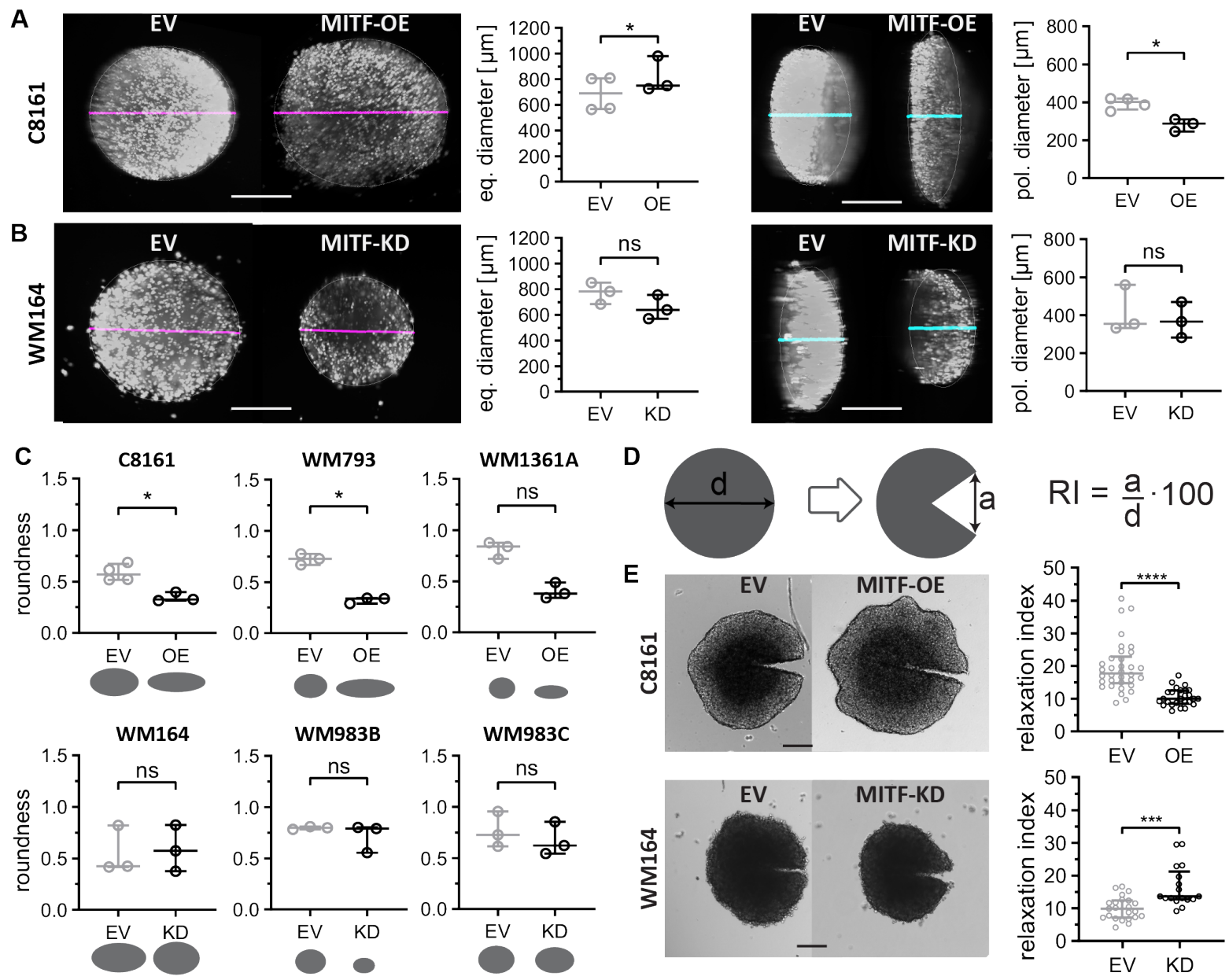

Figure 4: MITF overexpression decreases structural integrity and solid stress in melanoma

spheroids. Representative SPIM images (utilizing $m A G$ for fluorescence) and quantitation of polar and equatorial diameters of live (A) C8161 EV/MITF-OE and (B) WM164 ${ }^{\text {EV/MITF-KD }}$ spheroids. Magenta and cyan lines indicate measured equatorial and polar diameters, respectively, scale bars: $200 \mu \mathrm{m}$. (C) Spheroid roundness calculated as the ratio of equatorial to polar diameter and schematics showing spheroid silhouettes from a side-on view, demonstrating changes in spheroid size and roundness. (D) Schematic of solid stress assessment protocol and formula to calculate the relaxation index (RI). (E) Representative transmitted-light microscopy images of incised C8161 $1^{\text {EVIMITF-OE }}$ and WM164EV $V^{\text {MITF-KD }}$ spheroids and quantitation of their respective relaxation index. Scatter dot plot of median and interquartile range; analysis: Student t-test, $* * * * p<0.0001, * * * p<0.001, * * p<0.01, * p<0.05$, ns $p>0.05$ 
(roundness in average between 0.55 and 0.80 for endogenously MITF $^{\text {high }}$ spheroids, Fig. 4C) is physically limited to change towards a rounder morphology. To determine if these morphological alterations caused by MITF overexpression were accompanied by a change in cell density, we quantified the cell number in spheroids (Fig. S4D), which was unaffected by MITF modulation for C8161 and WM164. However, for WM793 and WM983B spheroids, a lower level of MITF was matched by a lower cell number and decreased volume (Fig. S4C), which may be explained by a larger $\mathrm{G}_{1}$-arrested area in spheroids of these two cell lines (Fig. S2A-D). This suggested that the MITF-driven morphological changes we observed in spheroids were not due to alterations in cell density.

To further assess the physical properties, we asked whether the morphological changes were associated with altered solid stress, i.e. the mechanical stress that is contained in and transmitted by the solid and elastic elements of the ECM and cells in the tumor microenvironment (Nia et al., 2018). To address this question, we incised spheroids to approximately $50 \%$ of their diameter and measured the incision opening to calculate the relaxation index (RI) indicative of solid stress (Fig. 4D) (Alessandri et al., 2013; Guillaume et al., 2019; Stylianopoulos et al., 2012). MITF overexpression significantly decreased the relaxation index of C8161 spheroids, supporting a reduced solid stress (Fig. 4E). Analogously, MITF knock-down of WM164 spheroids increased solid stress (Fig. 4E), despite the fact that it did not significantly alter their morphology (Fig. 4B). We demonstrate that high MITF levels result in flattening and solid stress reduction of melanoma spheroids, while cell density is not affected. These findings strongly suggest that MITF regulates structural integrity through altering solid stress in melanoma spheroids. 


\section{MITF expression affects molecular pathways involved in ECM organization}

To decipher the molecular mechanisms underlying, and potentially linking, the MITF-driven changes in architecture, solid stress and phenotypic heterogeneity, we performed a proteomics study based on MITF expression (C8161 ${ }^{\mathrm{MITF}-\mathrm{OE}}$ compared to $\mathrm{C} 8161^{\mathrm{EV}}$ spheroids and WM164 ${ }^{\mathrm{EV}}$ compared to WM164 ${ }^{\mathrm{MITF}-\mathrm{KD}}$ spheroids) to identify differentially expressed proteins (Fig. 5A). A total of 66 and 33 proteins were found to have statistically significant different levels between $\mathrm{EV}$ and $\mathrm{OE} / \mathrm{KD}$, respectively.

A

$B_{\text {pathway ID pathway description count in gene set FDR }}$

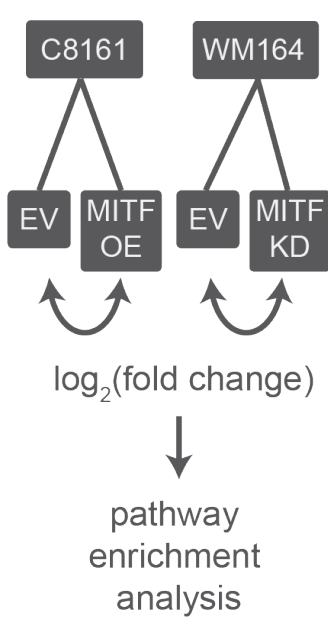

C8161 EV vs C8161 MITF-OE

GO:0030198 extracellular matrix organization $\quad 11$ of $296 \quad 0.0000119$

GO:0035987 endodermal cell differentiation $\quad 5$ of $41 \quad 0.00031$

GO:0009653 anatomical structure morphogenesis 20 of $1992 \quad 0.0024$

GO:0048646 anatomical structure formation (morphogenesis) 12 of $831 \quad 0.0063$

GO:0030154 cell differentiation $\quad 26$ of $3457 \quad 0.0073$

GO:0007275 multicellular organism development $\quad 30$ of $4726 \quad 0.0247$

GO:0048856 anatomical structure development $\quad 31$ of $5085 \quad 0.0350$

GO:0032502 developmental process 32 of $5401 \quad 0.0379$

GO:0071310 cellular response to organic substance $\quad 18$ of $2219 \quad 0.0400$

GO:0009888 tissue development $\quad 15$ of $1626 \quad 0.0400$

GO:0097435 supramolecular fiber organization $\quad 7$ of $383 \quad 0.0403$

GO:0060548 negative regulation of cell death 11 of $953 \quad 0.0403$

WM164 EV vs WM164 MITF-KD

GO:0072583 clathrin-dependent endocytosis

GO:0043062 extracellular structure organization

GO:0006898 receptor-mediated endocytosis

GO:0030198 extracellular matrix organization

$\begin{array}{ll}3 \text { of } 24 & 0.0178 \\ 6 \text { of } 339 & 0.0178 \\ 5 \text { of 209 } & 0.0178 \\ 5 \text { of 296 } & 0.0497\end{array}$

Figure 5: MITF expression affects levels of proteins involved in ECM and anatomical

structure. (A) Schematic of proteomics comparisons and downstream analysis. Lysis of whole (non-dissociated) spheroids assured that samples contained both proteins found within cells as well as within the ECM secreted by the cells.

(B) Gene Ontology pathways identified through STRING-based pathway enrichment analysis.

The STRING database was used to build a protein-protein network from the differentially expressed proteins and pathways enrichment was assessed on this network. Amongst the identified processes, ECM organization emerged as the predominant hit with a highly significant FDR value and presence in both cohorts of comparison (Fig. 5B). Cell-matrix 
interactions are key to tumor spheroid formation, compaction and architecture through the regulation of cell cytoskeleton contractility (Eyckmans and Chen, 2017; Ju et al., 2018). The ECM-integrin-cytoskeleton axis plays a major role in mechanotransduction, converting biomechanical cues into bio-chemical signals. Key to this axis are the multi-protein complexes known as focal adhesions that scaffold onto integrin transmembrane receptors, resulting in a bi-directional communication between the matrix and actomyosin contractile machinery (DuFort et al., 2011; Martino et al., 2018). We therefore proposed that the spheroid architectural differences at different MITF levels may be due to perturbations in cell adhesion, cell matrix and factors that regulate the cytoskeleton and actomyosin contractility.

Alterations in ECM and morphology likely correlate with alterations in mechanosensitive signaling. As focal adhesion kinase and myosin light chain are mechanosensitive signaling components associated with cell-matrix adhesion and of actomyosin contractility, respectively, and could explain the observed phenotypes, we next assessed their functionality upon changes in MITF level.

\section{MITF expression levels affect central components of mechanotransduction}

To answer whether MITF expression levels affect mechanosensitive signaling resulting in morphological alterations of spheroids, we investigated if actomyosin-dependent signaling was altered. As a measure for actomyosin contractility, we assessed the level and sub-cellular pattern of serine 19 phosphorylated myosin light chain 2 (pMLC2) via immunofluorescence in $\mathrm{C} 8161^{\mathrm{EV}}, \mathrm{C} 8161^{\mathrm{MITF}-\mathrm{OE}}, \mathrm{WM} 164^{\mathrm{EV}}$ and WM164 ${ }^{\mathrm{MITF}-\mathrm{KD}}$ cells (Fig. 6A,B). In C8161 ${ }^{\mathrm{MITF}-\mathrm{OE}}$ cells the cell mean fluorescence signal for pMLC2 was significantly decreased to approximately $75 \%$ of $\mathrm{C} 8161^{\mathrm{EV}}$ levels, whereas it was approximately $30 \%$ higher in WM164 ${ }^{\mathrm{MITF}-\mathrm{KD}}$ than in WM164 ${ }^{\mathrm{EV}}$ cells, suggesting an inverse relation between MITF level and contractility in these cells. 

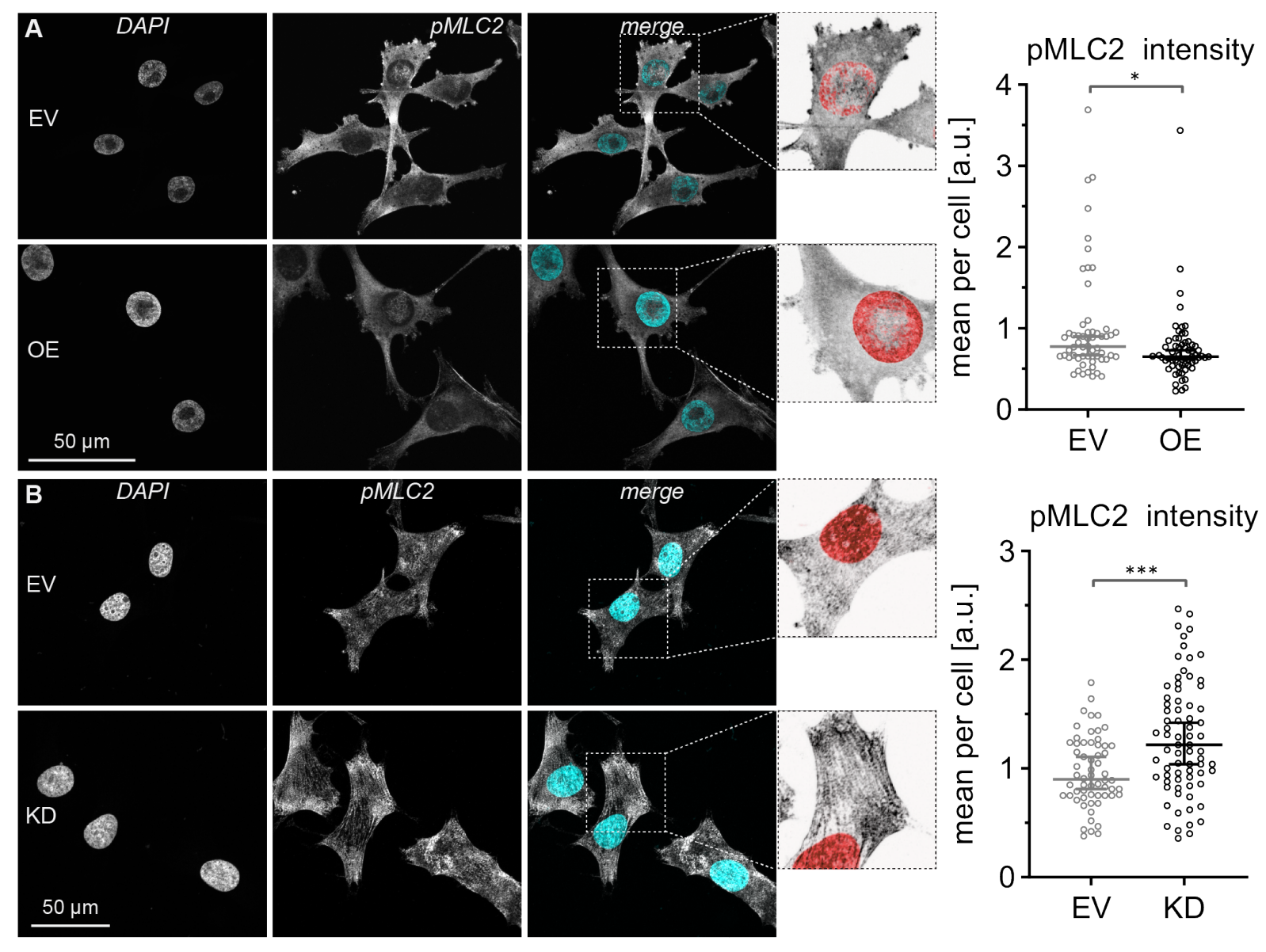
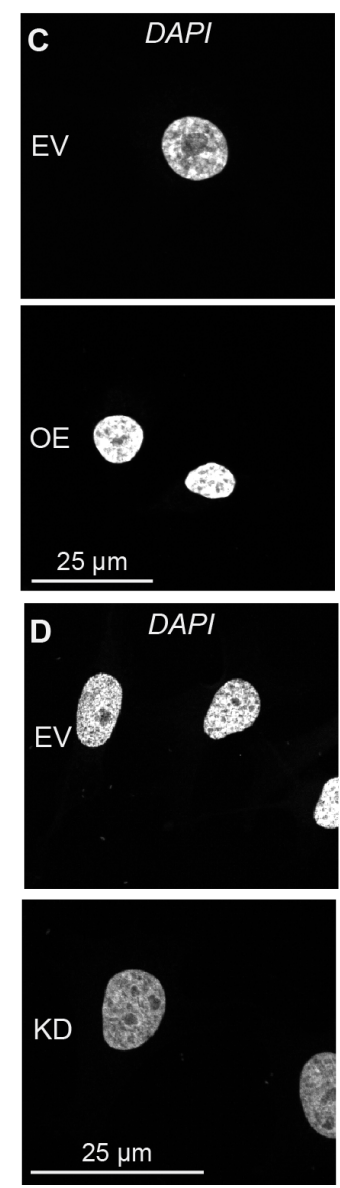
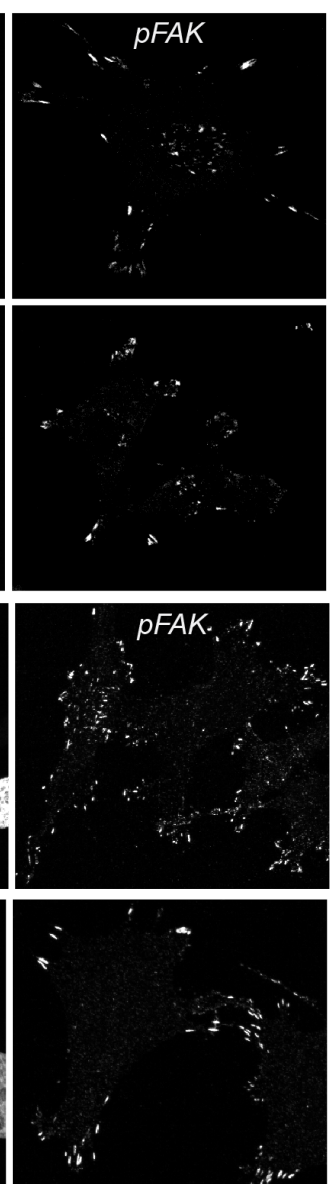
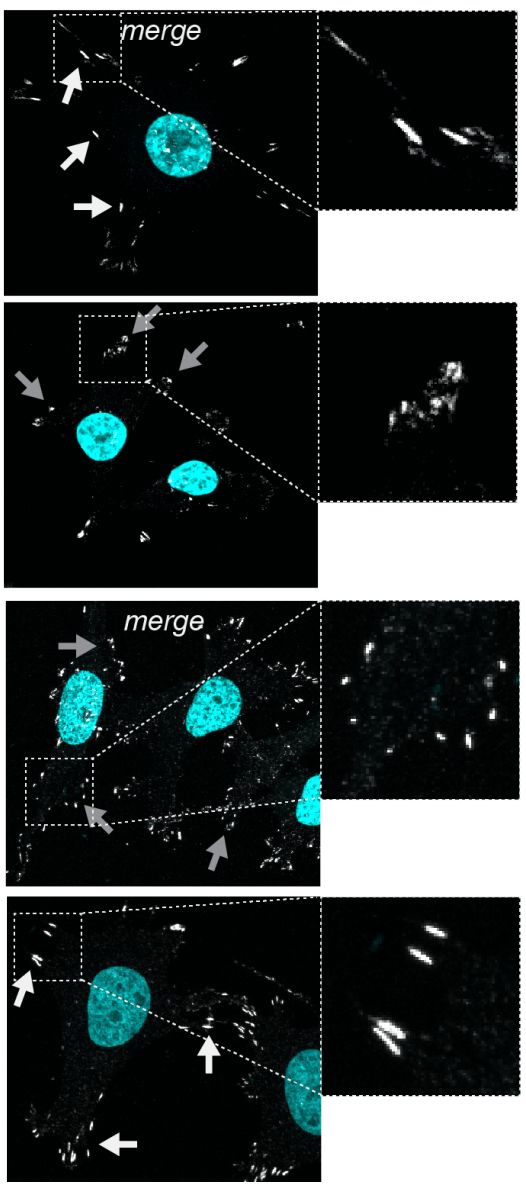

FA elongation

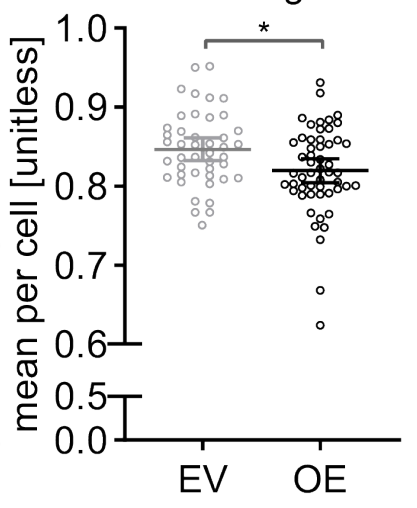

FA elongation

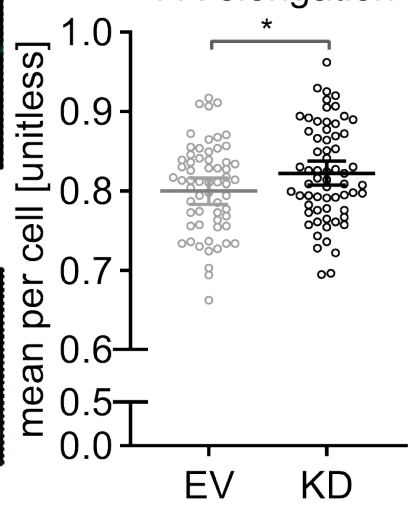




\section{Figure 6: MITF expression levels affect central components of mechanotransduction.} Representative immunofluorescence microscopy images of (A) pMLC2-S19 and pFAK-Y397 detection in $C 8161^{E V}$ versus C8161 $1^{\text {MITF-OE }}$ (A and $\boldsymbol{C}$ ) and WM164 ${ }^{E V}$ versus WM164 ${ }^{M I T F-K D}$ (B and D) cells and quantitation of pMLC2-S19 mean fluorescence signal per cell and the mean focal adhesion elongation per cell based on pFAK-Y397 signal. Higher magnification of pMLC2-stained cells in inverted colors for increased contrast of fiber-like pattern. White and gray arrows indicate elongated and rounded focal adhesions, respectively. Scatter dot plot of data median with 95\% CI; each dot represents a cell; $n>43$ cells from three independent experiments; analysis: Student t-test, ${ }^{*} p<0.05, * * * p<0.001$. FA, focal adhesion.

Furthermore, increased fiber-like pattern of pMLC2 was noticeable in WM164 ${ }^{\text {MITF-KD }}$ versus $\mathrm{WM} 164^{\mathrm{EV}}$ cells, characteristic of pMLC2 association with actin stress fibers and of contractile structures. We next visualized and compared focal adhesion morphology in the two cohorts by immunostaining the cells with an antibody against tyrosine 397 phosphorylated focal adhesion kinase (pFAK) (Fig. 6C,D), a tension-sensitive focal adhesion component that requires actomyosin contractility (Pasapera et al., 2010). The number of focal adhesions per cell remained unchanged both upon MITF overexpression and depletion (Fig. S6A,C), however we noticed alterations in adhesion morphology, resulting in more rounded adhesions in C8161 ${ }^{\mathrm{MITF}-\mathrm{OE}}$ than in $\mathrm{C} 8161^{\mathrm{EV}}$ and more elongated adhesions in WM164 ${ }^{\mathrm{MITF}-\mathrm{KD}}$ compared to WM164 ${ }^{\mathrm{EV}}$. This was confirmed by quantitation of focal adhesion morphology (Fig. 6C,D, S6B,D). As actomyosininduced contractility stabilizes adhesion formation and maturation, less elongated focal adhesions imply a decreased adhesion maturation and reduced actin fiber attachment to focal adhesions, which subsequently weakens cell contractility. Altogether, these findings suggest that high MITF levels alter mechano-sensitive signaling, resulting in both a decrease in 
actomyosin contractility and focal-adhesion dependent signaling, to drive the observed alteration in spheroid morphology.

\section{MITF expression levels impact cell dendricity and cell-mediated ECM contraction}

To understand the effect of the observed changes in myosin phosphorylation and focal adhesion maturation on spheroid architecture and cell cycle, we next studied cell morphology within spheroids. Membrane protrusions play a crucial role in cell-matrix adhesion via bi-directional signaling and physical connections between the ECM and the cell cytoskeleton (Zhang et al., 2008), which in turn are necessary for mechanosensing (Hoffman et al., 2011). We generated $\mathrm{C} 8161^{\mathrm{EV}}, \mathrm{C} 8161^{\mathrm{MITF}-\mathrm{OE}}, \mathrm{WM} 164^{\mathrm{EV}}$ and WM164 ${ }^{\mathrm{MITF}-\mathrm{KD}}$ spheroids with unstained cells and cells stained with CellTracker ${ }^{\mathrm{TM}}$ in a ratio of 50:1, to allow clearer visualization of cell architecture within 3D spheroids. Volumetric imaging was necessary to encompass the whole cell shape in three dimensions, and depth color-code was used to distinguish cells located at different $\mathrm{Z}$ depths. Confocal microscopy of CUBIC-cleared spheroids revealed a high degree of dendricity of $\mathrm{C} 8161^{\mathrm{EV}}$ cells when compared to $\mathrm{C} 8161^{\mathrm{MITF}-\mathrm{OE}}$ cells (Fig. 7A) and of WM164 ${ }^{\mathrm{MITF}-\mathrm{KD}}$ cells when compared to WM164 ${ }^{\mathrm{EV}}$ cells (Fig. 7B), suggesting an inverse association of MITF level with dendrite projections and ECM adhesion in these cells.

To assess the effect of reduced mechanosensitive signaling and actomyosin contractility on the cells' ability to organize the surrounding matrix, we performed a matrix contraction assay where we embedded $\mathrm{C} 8161^{\mathrm{EV}}, \mathrm{C} 8161^{\mathrm{MITF}-\mathrm{OE}}, \mathrm{WM} 164^{\mathrm{EV}}$ and $\mathrm{WM} 164^{\mathrm{MITF}-\mathrm{KD}}$ cells in collagen and measured the matrix plug area as a function of time. Over a 4-day period, C8161 1 MITF-OE cells showed a $35 \%$ decrease in their ability to contract the collagen plug compared to $\mathrm{C} 8161^{\mathrm{EV}}$ cells (Fig. 7C), whereas the WM164 ${ }^{\mathrm{MITF}-\mathrm{KD}}$ cells contracted the collagen plug $62 \%$ more effectively than WM164 ${ }^{\mathrm{EV}}$ (Fig. 7D). This indicated that $\mathrm{MITF}^{\text {high }}$ melanoma cells have an impaired ability to contract the surrounding matrix. 

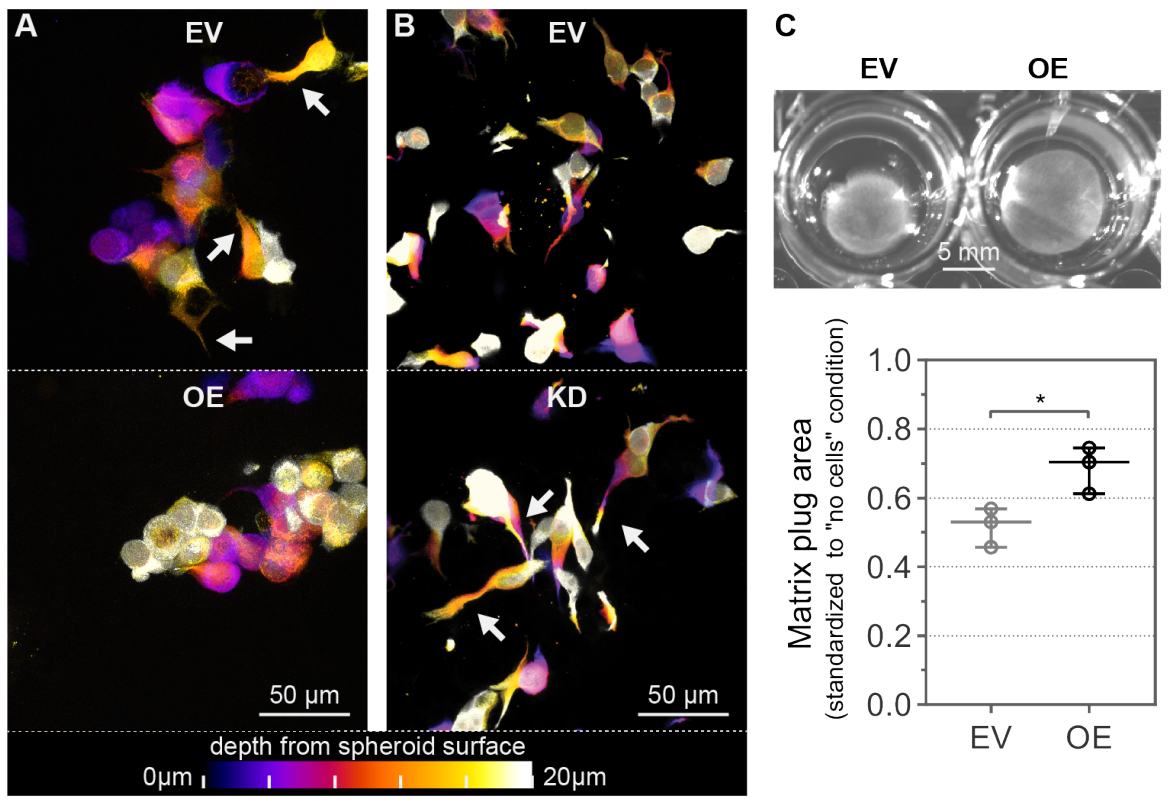

D EV KD
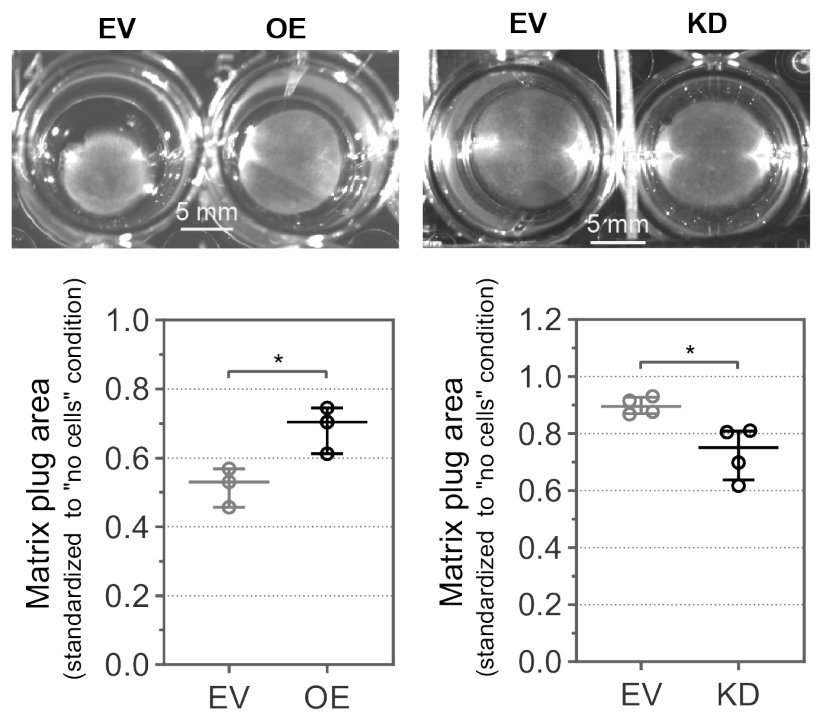

Figure 7: MITF expression levels impact cell dendricity and cell-mediated ECM contraction.

Representative Z-stack maximum intensity projection depth color-coded confocal images of (A) $C 8161^{E V}$ and $C 8161^{\text {MITF-OE }}$ and (B) WM164 $4^{E V}$ and WM164 $4^{\text {MITF-KD }}$ spheroid cells $(n=3$ independent experiments). Arrows indicate dendrites. Representative images of matrix contraction assay and quantitation of collagen gel plug contraction for (C) C8161 and (D) WM164 cells. Data normalized to an acellular collagen control; scatter dot plot of data median and interquartile range; each dot represents the mean of an independent experiment; $n=3$ experiments; analysis: paired Student t-test, ${ }^{*} p<0.05$.

These findings, together with our observations that myosin phosphorylation and tensiondependent focal adhesion morphology are decreased in MTFF $^{\text {high }}$ populations, support the hypothesis of an inverse regulation of mechanotransduction by MITF.

ROCK inhibition phenocopies the effects of high MITF levels on melanoma cells and spheroids

We demonstrated an inverse relation between MITF levels and MLC phosphorylation (Fig. 6A,B). Phosphorylation of MLC plays a key role in the Rho-ROCK-myosin pathway, which 
regulates actin-based machineries that drive mechanosensitive alterations in cell and tissue morphology. Dysregulation of Rho-ROCK-myosin signaling has been extensively linked to cancer (Chin et al., 2015; Martino et al., 2018; Morgan-Fisher et al., 2013). Recently, RhoROCK-myosin signaling has been shown to play a central role in melanoma acquired therapy resistance (Orgaz et al., 2020). Furthermore, this mechanism is known to influence spheroid architecture and compaction (Napolitano et al., 2007; Sodek et al., 2009; Tzanakakis et al., 2001). As we have shown an inverse impact of MITF expression level on mechanosensitive signaling and cell contractility, we hypothesized that this phenomenon is driven by the RhoROCK-myosin pathway. To test this hypothesis, we studied the effect of ROCK inhibition on $\mathrm{MITF}^{\text {low }}$ cells and spheroids $\left(\mathrm{C} 8161^{\mathrm{EV}}\right.$ and WM164 $\left.{ }^{\mathrm{MITF}-\mathrm{KD}}\right)$ using the small molecule ROCK inhibitor Y27632, to assess whether reducing Rho-ROCK-myosin pathway activity could mimic and rescue the effect of MITF overexpression and depletion, respectively. Indeed, similar to $\mathrm{C} 8161^{\mathrm{MITF}-\mathrm{OE}}$ cells, ROCK-inhibited $\mathrm{C} 8161^{\mathrm{EV}}$ cells $(\mathrm{EV}+\mathrm{Y})$ contracted the collagen matrix significantly less than untreated $\mathrm{C} 8161^{\mathrm{EV}}$ cells, whereas ROCK inhibition of WM164 ${ }^{\text {MITF-KD }}$ cells $(\mathrm{KD}+\mathrm{Y})$ neutralized the increased matrix-contraction ability conferred by MITF depletion (Fig. 8A). In spheroids, ROCK inhibition of $\mathrm{C} 8161^{\mathrm{EV}}$ and WM164 ${ }^{\text {MITF-KD }}$ also phenocopied and reverted, respectively, cell morphology change caused by MITF overexpression, in particular, cell dendricity, which was prominent in untreated $\mathrm{C} 8161^{\mathrm{EV}}$ and WM164 ${ }^{\text {MITF-KD }}$ spheroids (Fig. 8B). We then assessed spheroid tensile stress, which was reduced to similar levels both by MITF overexpression and ROCK inhibition (Fig. 8C). Inhibition of ROCK in WM164 ${ }^{\mathrm{MITF}-\mathrm{KD}}$ spheroids returned solid stress to a lower level comparable to that observed for $\mathrm{WM} 164^{\mathrm{EV}}$ spheroids (Fig. 8C). By SPIM analysis we confirmed that, similar to $\mathrm{C} 8161^{\mathrm{MITF}-\mathrm{OE}}$ spheroids, the equatorial diameter of ROCK-inhibited $\mathrm{C} 8161^{\mathrm{EV}}$ spheroids was increased, while the polar diameter was reduced, compared to $\mathrm{C} 8161^{\mathrm{EV}}$ (Fig. 8D). We finally asked whether the effect of ROCK inhibition on tensile stress was 

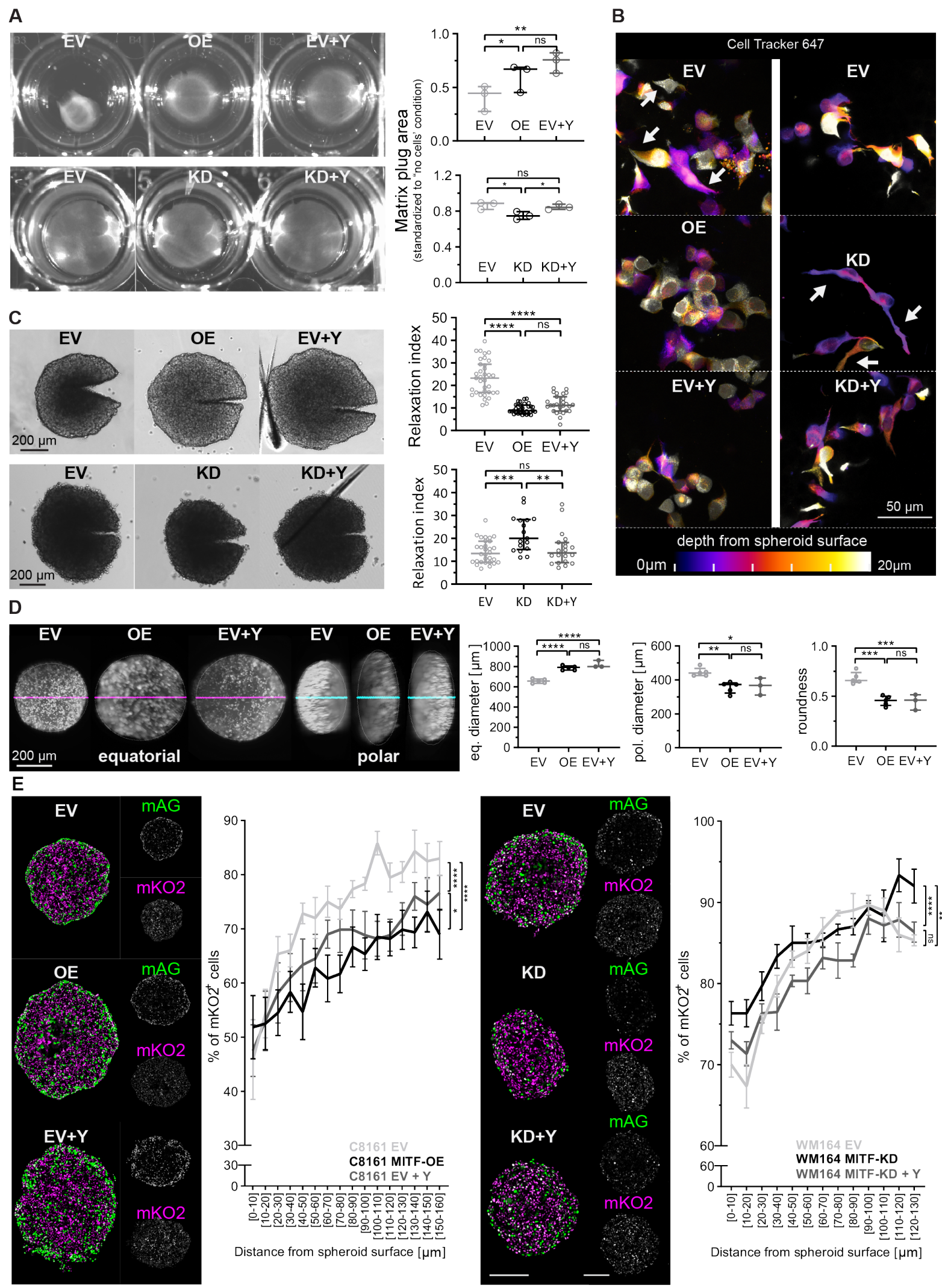

Figure 8: ROCK inhibition phenocopies the effects of high MITF levels on melanoma cells

and spheroids. $C 8161^{E V}, C 8161^{M I T F-O E}, W M 164^{E V}$ and WM164 ${ }^{M I T F-K D}$ cells were cultured with or without $10 \mu M$ ROCK inhibitor Y27632 (+Y). (A) Representative images of matrix 
contraction assay and quantitation of matrix plug contraction. (B) Representative depth colorcoded confocal images of spheroid cells. Arrows indicate dendrites. (C) Representative transmitted-light microscopy images of incised spheroids and quantitation of their relaxation index. (D) Representative SPIM images (utilizing mAG for fluorescence) of spheroids from top view (pol) and side view (eq) and quantitation of equatorial and polar spheroid diameters and their ratio (roundness). Magenta and cyan lines indicate measured equatorial and polar diameters, respectively. (E) Representative $m A G$ and $m K O 2$ fluorescence images of spheroid equatorial cryosections and analysis of spatial distribution of $G_{1}$ cells. Graphs show the percentage of $m \mathrm{KO}^{+}$cells $\left(\mathrm{mKO} 2^{+}\right.$cells $/\left(\mathrm{mKO}^{+}\right.$cells $+\mathrm{mAG}^{+}$cells $\left.)\right)$as a function of radial distance from the spheroid surface. Scatter dot plot of data median and interquartile range with one-way ANOVA analysis for all graphs except (D), mean \pm SEM with two-way ANOVA analysis for the effect of MITF and or Y27632 on \% of mKO2+cells. $N \geq 3 ; * * * * p<0.0001$, $* * * p<0.001 * *, p<0.01, * p<0.05, n s, p \geq 0.05$.

accompanied by changes in phenotypic heterogeneity as well, to support a mechanistic link between the two phenomena. We found that ROCK inhibition, similar to MITF overexpression, significantly reduced the $\mathrm{G}_{1}$-arrested area in $\mathrm{C} 8161^{\mathrm{EV}}$ spheroids, confirming phenocopy of MITF-induced loss of phenotypic heterogeneity (Fig. 8E). Similarly, the increase in phenotypic heterogeneity driven by MITF depletion in WM164 spheroids was reverted by ROCK inhibition which led to a reduction of the G1-arrested area (Fig. 8E).

Altogether, our findings show that ROCK inhibition phenocopies the effects of MITF overexpression on the melanoma cells' ability to sense and respond to the microenvironment, leading to a decreased cell and ECM contraction. This was the case also at spheroid level, where MITF overexpressing spheroids and ROCK-inhibited spheroids were both flatter and with a lower tensile stress and demonstrated decreased phenotypic heterogeneity. This 
indicates that spheroid cell mechanotransduction, spheroid architecture and spheroid phenotypic heterogeneity are interrelated processes mediated by MITF and Rho-ROCKmyosin signaling. We thus conclude that in melanoma, MITF-dependent regulation of mechanosensitive signaling results in tumor architectural changes, that in turn impact phenotypic heterogeneity.

\section{Discussion}

MITF has been largely implicated in melanoma phenotypic heterogeneity, yet its functional role is only partially elucidated and at times even controversial. Most studies have either focused on the role of MITF in adherent cell culture, omitting the tumor 3D microenvironment, or in vivo, with limitations of deciphering detailed underlying mechanisms (Beaumont et al., 2013). Our 3D melanoma models allow us to establish an in-depth mechanistic understanding of this process, with a focus on important aspects provided by the three-dimensional tumor environment, such as tumor architecture and solid stress. In this study, we demonstrate that MITF-mediated extracellular matrix alterations regulate phenotypic heterogeneity in melanoma via the Rho-ROCK-myosin signaling pathway.

MITF-driven dynamic heterogeneity implies phenotype switching whereby melanoma cells reversibly switch between MITF high and low expression characterized by different proliferative and biological states (Hoek et al., 2008a). Therefore, distribution of differentially cycling cell clusters can be used as a surrogate for dynamic heterogeneity (Haass, 2015; Haass et al., 2014). The MITF rheostat model plays a complex role in melanoma cell proliferation through a number of direct effects on cell cycle proteins (Carreira et al., 2005; Carreira et al., 2006; Du et al., 2004; Loercher et al., 2005; Strub et al., 2011). However, MITF can also indirectly influence proliferation by affecting processes that regulate cell homeostasis, for instance metabolism, autophagy and survival (Goding and Arnheiter, 2019). As opposed to 
direct effects on cell cycle proteins, the latter scenario relies on an adaptation to microenvironmental cues to manifest. This mechanism of action appears to apply to the control of phenotypic heterogeneity by MITF that we have identified in this work. Indeed, modulation of MITF expression did not impact the cell cycle profile in adherent culture, but only when the cells were surrounded by a $\mathrm{G}_{1}$-arrest promoting environment, as typically found in 3D models in vitro and in vivo and characterized by paucity of oxygen, high cell-cell contact and spatial confinement (Desmaison et al., 2018; Hoarau-Vechot et al., 2018).

We found that the degree and pattern of hypoxia in spheroids with high or low MITF expression excluded oxygen availability as a cause of the observed changes in phenotypic heterogeneity. However, we demonstrate that in spheroids composed of MITF ${ }^{\text {high }}$ melanoma cells, cells are able to proliferate in hypoxia, implying that MITF reduces hypoxia-triggered cell cycle arrest. In melanoma cells, gene regulation in response to hypoxia has been recently reported to be mitigated by MITF expression (Louphrasitthiphol et al., 2019). MITF destabilizes HIF1 $\alpha$ through upregulation of SDHB expression, one of four subunits of the succinate dehydrogenase enzyme, and consequent depletion of succinate, an inhibitor of HIF $1 \alpha$ degradation by prolyl hydroxylase. Conversely, downregulation of MITF by hypoxia through HIF1 $\alpha$ and the transcription factor DEC1 has also been reported, which led to decreased proliferation (Cheli et al., 2012; Feige et al., 2011). This supports our findings, in which high MITF might override the trigger from a low oxygen environment to induce $G_{1}$-arrest under hypoxia, either by preventing HIF1 $\alpha$-stabilization or MITF suppression. Alternatively, MITF could mediate protection from hypoxia-induced $\mathrm{G}_{1}$-arrest in an indirect manner, for instance via alteration of the microenvironment, rather than through cell intrinsic changes of sensitivity to oxygen deprivation.

This latter scenario is supported by the alteration of ECM organization whose investigation was prompted by the MITF-driven morphology and solid stress changes. We showed that 
depending on MITF levels, cells differentially contract the surrounding matrix which putatively results in different ECM organization in spheroids. This is supported by our proteomics findings and collagen contraction assays. Altered cell dendricity, focal adhesion morphology and MLC2 phosphorylation support this impact on cell-ECM interaction and the cells' ability to contract the ECM.

Differentiation, cell cycle, survival, invasion, DNA-damage repair, metabolism and lysosome biogenesis are known MITF-related biological functions (Cheli et al., 2010; Goding and Arnheiter, 2019; Kawakami and Fisher, 2017). While there are studies reporting interaction of MITF with cell-cell adhesion proteins such as E-Cadherin (Kim et al., 2013), CEACAM1 (Ullrich et al., 2015) and Mel-CAM (Koch et al., 2001), we did not find any report linking MITF to cell-ECM communication in melanoma. This could be due to a large majority of studies having employed 2D culture, therefore lacking the influence of a 3D microenvironment and where typically only cell-contained and cell-bound components are analyzed.

Shifting of traditional cancer perspectives to comprise the influence of the tumor microenvironment on cancer biology benefitted research with a more accurate and comprehensive understanding of tumor cell biology (Eble and Niland, 2019; Poltavets et al., 2018; Walker et al., 2018). Excitingly, our findings on the impact of MITF on cell morphology, focal adhesion shape, pMLC2 level and ability to contract the ECM point towards the putative involvement of ECM signal integration via cytoskeleton contractility. This phenomenon is mediated by actin stress fibers, rich in myosin II motors, which attach to focal adhesion complexes and transmit forces from the surrounding ECM to the cells and vice versa (Cramer et al., 1997; Pellegrin and Mellor, 2007), allowing remodeling, organization and contraction, of the surrounding ECM. Contractile force generation is mediated by the Rho-ROCK-myosin signaling pathway, whose inhibition we found to phenocopy the spheroid and cell phenotype caused by MITF overexpression. Taken together, our findings imply an inverse link between 
the Rho-ROCK signaling axis and MITF level, which is in line with increased Rho activity, ROCK-dependent invasiveness and increased myosin phosphorylation found in melanoma cells where MITF was depleted (Arozarena et al., 2011; Bianchi-Smiraglia et al., 2017; Carreira et al., 2006).

There is a growing body of evidence on the impact of mechanical cues of the microenvironment on cancer cells biology, including cancer cell plasticity (Poltavets et al., 2018). Extensive investigation has been carried out on the effects of ECM stiffness on tumorigenesis, and the contribution of solid stress to tumor biology is an exciting emerging field of research. In our study, in addition to decreased phenotypic heterogeneity, high MITF expression levels drove two main phenotypes: morphological relaxation and decreased solid stress. It has been shown that compressive stress in cancer cell spheroids led to $\mathrm{G}_{1}$-arrest via p $27^{\mathrm{kip}}$ upregulation, which in turn was triggered by cell volume reduction (Delarue et al., 2014). Interestingly, the extent of these three features was not homogenous across the spheroid but presented as a gradient increasing from the periphery towards the center. The same group showed that this particular spatial pattern was due to anisotropic cell arrangement (orientation of cell major axis) across the spheroid and dependent on ROCK-mediated contractility (Dolega et al., 2017).

Our results are in agreement with these findings, whereby solid stress and phenotypic heterogeneity changed simultaneously in our spheroids when MITF expression was altered. We found both the distribution of cell orientation and of hypoxia could contribute to the centrifugal pattern of phenotypic heterogeneity (irrespective of MITF expression). In fact, we observed radial dissemination of both features, with cells with high anisotropy (major axis perpendicular to radius) and low hypoxia located closer to the spheroid rim. We show here that both solid stress and phenotypic heterogeneity depend on ROCK activation.

Elevated activity of the Rho-ROCK-myosin signaling axis is typically associated with increased proliferation via promotion of cell contractility, cell adhesion, cytokinesis, oncogene 
activation and regulation of cell cycle proteins. Nevertheless, there is a number of studies reporting an opposite role of the Rho-ROCK-myosin signaling pathway through negative feedback on growth factor signaling (Nakashima et al., 2010) and promotion of tumor suppressor genes such as PTEN (Fusella et al., 2014; Yang and Kim, 2012), p21 (Olson et al., 1998; Taubenberger et al., 2019) and p2 $7^{\text {kip }}$ (Hu et al., 1999; Vidal et al., 2002). It has been speculated that ROCK contractility may simply act as a necessary mediator of cell structural changes which in turn would impact cell cycle protein levels, for instance $\mathrm{p} 27^{\mathrm{kip}}$ regulation by PKC $\alpha$-PKB-FoxO signaling that is initiated by stretch-stress-activated calcium channels (Delarue et al., 2014). Another suggested mechanism is through a negative regulatory feedback loop between ROCK and p21/p2 $7^{\mathrm{kip}}$ (Besson et al., 2008).

We propose that MITF controls ECM organization and mechanical properties of melanoma through regulation of cell-mediated matrix contraction. By acting as a scaffold and a capsule, the ECM in turn controls spheroid solid stress and physical pressure undergone by cells, regulating their ROCK-mediated contractility and ultimately their proliferation. Oxygen level, cell arrangement and pressure are all likely to contribute to the phenotypic heterogeneity pattern. We believe that radial characteristics of proliferation arise from the centrifugal distribution of hypoxia and cell orientation (MITF-independent), whereas MITF controls the gradient slope by modulating mechanical stress throughout the spheroid (i.e. high MITF level leads to a less steep gradient from proliferation to $\mathrm{G}_{1}$-arrest).

How MITF-triggered mechanical stress controls $\mathrm{G}_{1}$-arrest can only be inferred from other studies and requires a distinct study for further elucidation. It would also be interesting to further unravel how ECM mechanical characteristics are altered by MITF across the spheroid, how these changes lead to modification of spheroid solid stress and the potential implications of the changes in tumor proliferation, migration and metastasis. 
Orgaz and colleagues have recently demonstrated the role of ROCK inhibition in acquired resistance to both targeted and immune therapy (Orgaz et al., 2020). Our data demonstrate that the Rho-ROCK-myosin axis is differentially activated depending on MITF levels. Inhibiting the activity of the Rho-ROCK-myosin axis in MITF $^{\text {low }}$ melanomas could thus improve MAPK pathway inhibition by controlling the presence of G1-arrested or slow-cycling cell populations that are putatively prone to develop therapy resistance. Furthermore, ROCK inhibition might change the tumor/ECM architecture to allow better access of immune cells to the tumor cells.

This work demonstrates a novel role of MITF in melanoma phenotypic heterogeneity, it provides a better understanding of the biology of this crucial melanoma transcription factor and new putative targets (e.g. Rho-ROCK-myosin signaling axis and ECM organization and mechanical properties) to potentially control its impact on phenotypic heterogeneity.

\section{Acknowledgments}

This research was carried out at the Translational Research Institute (TRI), Woolloongabba, QLD, and in part at the Centenary Institute (CI), Camperdown, NSW, Australia. TRI is supported by a grant from the Australian Government. We thank TRI's and CI's core facilities for outstanding technical support (microscopy, flow cytometry, proteomics, histology and animal facility). We thank Prof. Atsushi Miyawaki, RIKEN, Wako-city, Japan, for providing the FUCCI constructs, Prof. Meenhard Herlyn and Ms. Patricia Brafford, The Wistar Institute, Philadelphia, PA, for providing cell lines, Ms. Dorothy Loo-Oey, TRI, for the proteomics study, and Prof. Jochen Guck, Max-Planck Institute for the Science of Light, Erlangen, and Dr. Anna Taubenberger, Technische Universität Dresden, Germany, for their intellectual input. N.K.H. is a Cameron fellow of the Melanoma and Skin Cancer Research Institute, Australia. K.A.B. is a fellow of Cancer Institute New South Wales (13/ECF/1-39). D.S.H. is a David Sainsbury Fellow of the National Centre for the Replacement, Refinement and Reduction of 
Animals in Research. This work was supported by project grants to N.K.H.: APP1003637 and APP1084893 (National Health and Medical Research Council); RG 09-08 and RG 13-06 (Cancer Council New South Wales), 570778 and 1051996 (Priority-driven collaborative cancer research scheme/Cancer Australia/Cure Cancer Australia Foundation), 08/RFG/1-27 (Cancer Institute New South Wales), and Meehan Project Grant 0211742017002565.

\section{Author Contributions}

Conceptualization, Supervision, Project Administration and Funding Acquisition, N.K.H.; Intellectual Contribution to Conceptualization and Funding Acquisition: W.W., H.S., B.G.; Methodology, N.K.H., E.K.S.; Investigation, L.S., C.A.T.-M., G.P.G., D.S.H., K.A.B., R.J.J., G.C.V., M.E.F., S.M.D., N.K.H.; Validation and Formal Analysis, L.S., C.A.T.-M., G.P.G., D.S.H., K.A.B., R.J.J., N.M., N.K.H.; Data Curation: L.S., N.K.H.; Writing - Original Draft, L.S., N.K.H.; Writing - Review \& Editing, L.S., A.G.S., S.J.S., H.S., W.W., B.G., N.K.H.

\section{Declaration of Interests}

The authors declare no conflict of interests.

\section{References}

Ahmed, F., and Haass, N. K. (2018). Microenvironment-Driven Dynamic Heterogeneity and Phenotypic Plasticity as a Mechanism of Melanoma Therapy Resistance. Front Oncol 8, 173. Alessandri, K., Sarangi, B. R., Gurchenkov, V. V., Sinha, B., Kiessling, T. R., Fetler, L., Rico, F., Scheuring, S., Lamaze, C., Simon, A., et al. (2013). Cellular capsules as a tool for multicellular spheroid production and for investigating the mechanics of tumor progression in vitro. Proceedings of the National Academy of Sciences of the United States of America 110, 14843-14848.

Arozarena, I., Bischof, H., Gilby, D., Belloni, B., Dummer, R., and Wellbrock, C. (2011). In melanoma, beta-catenin is a suppressor of invasion. Oncogene 30, 4531-4543.

Arozarena, I., and Wellbrock, C. (2017). Overcoming resistance to BRAF inhibitors. Ann Transl Med 5, 387.

Bai, X., Fisher, D. E., and Flaherty, K. T. (2019). Cell-state dynamics and therapeutic resistance in melanoma from the perspective of MITF and IFNgamma pathways. Nat Rev Clin Oncol 16, 549-562. 
Beaumont, K. A., Hill, D. S., Daignault, S. M., Lui, G. Y., Sharp, D. M., Gabrielli, B., Weninger, W., and Haass, N. K. (2016). Cell Cycle Phase-Specific Drug Resistance as an Escape Mechanism of Melanoma Cells. J Invest Dermatol 136, 1479-1489.

Beaumont, K. A., Mohana-Kumaran, N., and Haass, N. K. (2013). Modeling Melanoma In Vitro and In Vivo. Healthcare (Basel) 2, 27-46.

Bertolotto, C., Lesueur, F., Giuliano, S., Strub, T., de Lichy, M., Bille, K., Dessen, P., d'Hayer, B., Mohamdi, H., Remenieras, A., et al. (2011). A SUMOylation-defective MITF germline mutation predisposes to melanoma and renal carcinoma. Nature 480, 94-98.

Besson, A., Dowdy, S. F., and Roberts, J. M. (2008). CDK inhibitors: cell cycle regulators and beyond. Developmental cell 14, 159-169.

Bianchi-Smiraglia, A., Bagati, A., Fink, E. E., Moparthy, S., Wawrzyniak, J. A., Marvin, E. K., Battaglia, S., Jowdy, P., Kolesnikova, M., Foley, C. E., et al. (2017). Microphthalmiaassociated transcription factor suppresses invasion by reducing intracellular GTP pools. Oncogene 36, 84-96.

Carreira, S., Goodall, J., Aksan, I., La Rocca, S. A., Galibert, M. D., Denat, L., Larue, L., and Goding, C. R. (2005). Mitf cooperates with Rb1 and activates p21Cip1 expression to regulate cell cycle progression. Nature 433, 764-769.

Carreira, S., Goodall, J., Denat, L., Rodriguez, M., Nuciforo, P., Hoek, K. S., Testori, A., Larue, L., and Goding, C. R. (2006). Mitf regulation of Dial controls melanoma proliferation and invasiveness. Genes Dev 20, 3426-3439.

Cheli, Y., Giuliano, S., Fenouille, N., Allegra, M., Hofman, V., Hofman, P., Bahadoran, P., Lacour, J. P., Tartare-Deckert, S., Bertolotto, C., and Ballotti, R. (2012). Hypoxia and MITF control metastatic behaviour in mouse and human melanoma cells. Oncogene 31, 2461-2470. Cheli, Y., Ohanna, M., Ballotti, R., and Bertolotto, C. (2010). Fifteen-year quest for microphthalmia-associated transcription factor target genes. Pigment cell \& melanoma research 23, 27-40.

Chiaverini, C., Beuret, L., Flori, E., Busca, R., Abbe, P., Bille, K., Bahadoran, P., Ortonne, J. P., Bertolotto, C., and Ballotti, R. (2008). Microphthalmia-associated transcription factor regulates RAB27A gene expression and controls melanosome transport. J Biol Chem 283, 12635-12642.

Chin, V. T., Nagrial, A. M., Chou, A., Biankin, A. V., Gill, A. J., Timpson, P., and Pajic, M. (2015). Rho-associated kinase signalling and the cancer microenvironment: novel biological implications and therapeutic opportunities. Expert Rev Mol Med 17, e17.

Cramer, L. P., Siebert, M., and Mitchison, T. J. (1997). Identification of novel graded polarity actin filament bundles in locomoting heart fibroblasts: implications for the generation of motile force. The Journal of cell biology 136, 1287-1305.

Delarue, M., Montel, F., Vignjevic, D., Prost, J., Joanny, J. F., and Cappello, G. (2014). Compressive stress inhibits proliferation in tumor spheroids through a volume limitation. Biophys J 107, 1821-1828.

Desmaison, A., Guillaume, L., Triclin, S., Weiss, P., Ducommun, B., and Lobjois, V. (2018). Impact of physical confinement on nuclei geometry and cell division dynamics in 3D spheroids. Sci Rep 8, 8785.

Dolega, M. E., Delarue, M., Ingremeau, F., Prost, J., Delon, A., and Cappello, G. (2017). Cell-like pressure sensors reveal increase of mechanical stress towards the core of multicellular spheroids under compression. Nature communications 8, 14056.

Du, J., Widlund, H. R., Horstmann, M. A., Ramaswamy, S., Ross, K., Huber, W. E., Nishimura, E. K., Golub, T. R., and Fisher, D. E. (2004). Critical role of CDK2 for melanoma growth linked to its melanocyte-specific transcriptional regulation by MITF. Cancer Cell 6 , 565-576. 
DuFort, C. C., Paszek, M. J., and Weaver, V. M. (2011). Balancing forces: architectural control of mechanotransduction. Nat Rev Mol Cell Biol 12, 308-319.

Eble, J. A., and Niland, S. (2019). The extracellular matrix in tumor progression and metastasis. Clin Exp Metastasis 36, 171-198.

Eyckmans, J., and Chen, C. S. (2017). 3D culture models of tissues under tension. J Cell Sci 130, 63-70.

Feige, E., Yokoyama, S., Levy, C., Khaled, M., Igras, V., Lin, R. J., Lee, S., Widlund, H. R., Granter, S. R., Kung, A. L., and Fisher, D. E. (2011). Hypoxia-induced transcriptional repression of the melanoma-associated oncogene MITF. Proceedings of the National Academy of Sciences of the United States of America 108, E924-933.

Fiore, A., Ribeiro, P. F., and Bruni-Cardoso, A. (2018). Sleeping Beauty and the Microenvironment Enchantment: Microenvironmental Regulation of the ProliferationQuiescence Decision in Normal Tissues and in Cancer Development. Front Cell Dev Biol 6, 59.

Fusella, F., Ferretti, R., Recupero, D., Rocca, S., Di Savino, A., Tornillo, G., Silengo, L., Turco, E., Cabodi, S., Provero, P., et al. (2014). Morgana acts as a proto-oncogene through inhibition of a ROCK-PTEN pathway. The Journal of pathology 234, 152-163.

Garraway, L. A., Widlund, H. R., Rubin, M. A., Getz, G., Berger, A. J., Ramaswamy, S., Beroukhim, R., Milner, D. A., Granter, S. R., Du, J., et al. (2005). Integrative genomic analyses identify MITF as a lineage survival oncogene amplified in malignant melanoma. Nature 436, 117-122.

Goding, C. R., and Arnheiter, H. (2019). MITF-the first 25 years. Genes \& development 33, 983-1007.

Gray-Schopfer, V., Wellbrock, C., and Marais, R. (2007). Melanoma biology and new targeted therapy. Nature 445, 851-857.

Grzywa, T. M., Paskal, W., and Wlodarski, P. K. (2017). Intratumor and Intertumor

Heterogeneity in Melanoma. Transl Oncol 10, 956-975.

Guillaume, L., Rigal, L., Fehrenbach, J., Severac, C., Ducommun, B., and Lobjois, V. (2019). Characterization of the physical properties of tumor-derived spheroids reveals critical insights for pre-clinical studies. Sci Rep 9, 6597.

Guo, W., and Giancotti, F. G. (2004). Integrin signalling during tumour progression. Nature reviews Molecular cell biology 5, 816-826.

Haass, N. K. (2015). Dynamic tumor heterogeneity in melanoma therapy: how do we address this in a novel model system? Melanoma Manag 2, 93-95.

Haass, N. K., Beaumont, K. A., Hill, D. S., Anfosso, A., Mrass, P., Munoz, M. A., Kinjyo, I., and Weninger, W. (2014). Real-time cell cycle imaging during melanoma growth, invasion, and drug response. Pigment Cell Melanoma Res 27, 764-776.

Haass, N. K., and Gabrielli, B. (2017). Cell cycle-tailored targeting of metastatic melanoma: Challenges and opportunities. Exp Dermatol 26, 649-655.

Hoarau-Vechot, J., Rafii, A., Touboul, C., and Pasquier, J. (2018). Halfway between 2D and Animal Models: Are 3D Cultures the Ideal Tool to Study Cancer-Microenvironment Interactions? Int J Mol Sci 19.

Hoek, K. S., Eichhoff, O. M., Schlegel, N. C., Dobbeling, U., Kobert, N., Schaerer, L., Hemmi, S., and Dummer, R. (2008a). In vivo switching of human melanoma cells between proliferative and invasive states. Cancer Res 68, 650-656.

Hoek, K. S., Schlegel, N. C., Brafford, P., Sucker, A., Ugurel, S., Kumar, R., Weber, B. L., Nathanson, K. L., Phillips, D. J., Herlyn, M., et al. (2006). Metastatic potential of melanomas defined by specific gene expression profiles with no BRAF signature. Pigment Cell Res 19, 290-302. 
Hoek, K. S., Schlegel, N. C., Eichhoff, O. M., Widmer, D. S., Praetorius, C., Einarsson, S. O., Valgeirsdottir, S., Bergsteinsdottir, K., Schepsky, A., Dummer, R., and Steingrimsson, E. (2008b). Novel MITF targets identified using a two-step DNA microarray strategy. Pigment cell \& melanoma research 21, 665-676.

Hoffman, B. D., Grashoff, C., and Schwartz, M. A. (2011). Dynamic molecular processes mediate cellular mechanotransduction. Nature 475, 316-323.

Hu, W., Bellone, C. J., and Baldassare, J. J. (1999). RhoA stimulates p27(Kip) degradation through its regulation of cyclin E/CDK2 activity. The Journal of biological chemistry 274, 3396-3401.

Jansen, K. A., Atherton, P., and Ballestrem, C. (2017). Mechanotransduction at the cellmatrix interface. Semin Cell Dev Biol 71, 75-83.

Ju, R. J., Stehbens, S. J., and Haass, N. K. (2018). The Role of Melanoma Cell-Stroma Interaction in Cell Motility, Invasion, and Metastasis. Front Med (Lausanne) 5, 307.

Kawakami, A., and Fisher, D. E. (2017). The master role of microphthalmia-associated transcription factor in melanocyte and melanoma biology. Laboratory investigation; a journal of technical methods and pathology 97, 649-656.

Kim, J. E., Leung, E., Baguley, B. C., and Finlay, G. J. (2013). Heterogeneity of expression of epithelial-mesenchymal transition markers in melanocytes and melanoma cell lines. Front Genet 4, 97.

Koch, M. B., Shih, I. M., Weiss, S. W., and Folpe, A. L. (2001). Microphthalmia transcription factor and melanoma cell adhesion molecule expression distinguish desmoplastic/spindle cell melanoma from morphologic mimics. Am J Surg Pathol 25, 58-64. Landy, S. D., and Szalay, A. S. (1993). Bias and variance of angular correlation functions. Astrophys J 412, 64-71.

Levy, C., Khaled, M., and Fisher, D. E. (2006). MITF: master regulator of melanocyte development and melanoma oncogene. Trends Mol Med 12, 406-414.

Loeffler-Wirth, H., Binder, H., Willscher, E., Gerber, T., and Kunz, M. (2018). Pseudotime Dynamics in Melanoma Single-Cell Transcriptomes Reveals Different Mechanisms of Tumor Progression. Biology (Basel) 7.

Loercher, A. E., Tank, E. M., Delston, R. B., and Harbour, J. W. (2005). MITF links differentiation with cell cycle arrest in melanocytes by transcriptional activation of INK4A. $\mathrm{J}$ Cell Biol 168, 35-40.

Louphrasitthiphol, P., Ledaki, I., Chauhan, J., Falletta, P., Siddaway, R., Buffa, F. M., Mole, D. R., Soga, T., and Goding, C. R. (2019). MITF controls the TCA cycle to modulate the melanoma hypoxia response. Pigment cell \& melanoma research.

Martino, F., Perestrelo, A. R., Vinarsky, V., Pagliari, S., and Forte, G. (2018). Cellular Mechanotransduction: From Tension to Function. Front Physiol 9, 824.

Miskolczi, Z., Smith, M. P., Rowling, E. J., Ferguson, J., Barriuso, J., and Wellbrock, C. (2018). Collagen abundance controls melanoma phenotypes through lineage-specific microenvironment sensing. Oncogene 37, 3166-3182.

Morgan-Fisher, M., Wewer, U. M., and Yoneda, A. (2013). Regulation of ROCK activity in cancer. The journal of histochemistry and cytochemistry : official journal of the Histochemistry Society 61, 185-198.

Nakashima, M., Adachi, S., Yasuda, I., Yamauchi, T., Kozawa, O., and Moriwaki, H. (2010). Rho-kinase regulates negatively the epidermal growth factor-stimulated colon cancer cell proliferation. International journal of oncology 36, 585-592.

Napolitano, A. P., Chai, P., Dean, D. M., and Morgan, J. R. (2007). Dynamics of the selfassembly of complex cellular aggregates on micromolded nonadhesive hydrogels. Tissue Eng 13, 2087-2094. 
Nazarian, R. M., Prieto, V. G., Elder, D. E., and Duncan, L. M. (2010). Melanoma biomarker expression in melanocytic tumor progression: a tissue microarray study. J Cutan Pathol 37 Suppl 1, 41-47.

Nia, H. T., Datta, M., Seano, G., Huang, P., Munn, L. L., and Jain, R. K. (2018). Quantifying solid stress and elastic energy from excised or in situ tumors. Nat Protoc 13, 1091-1105. Olson, M. F., Paterson, H. F., and Marshall, C. J. (1998). Signals from Ras and Rho GTPases interact to regulate expression of p21Waf1/Cip1. Nature 394, 295-299.

Orgaz, J. L., Crosas-Molist, E., Sadok, A., Perdrix-Rosell, A., Maiques, O., RodriguezHernandez, I., Monger, J., Mele, S., Georgouli, M., Bridgeman, V., et al. (2020). Myosin II Reactivation and Cytoskeletal Remodeling as a Hallmark and a Vulnerability in Melanoma Therapy Resistance. Cancer Cell 37, 85-103 e109.

Pasapera, A. M., Schneider, I. C., Rericha, E., Schlaepfer, D. D., and Waterman, C. M. (2010). Myosin II activity regulates vinculin recruitment to focal adhesions through FAKmediated paxillin phosphorylation. J Cell Biol 188, 877-890.

Pellegrin, S., and Mellor, H. (2007). Actin stress fibres. Journal of cell science 120, 34913499.

Pickup, M. W., Mouw, J. K., and Weaver, V. M. (2014). The extracellular matrix modulates the hallmarks of cancer. EMBO Rep 15, 1243-1253.

Poltavets, V., Kochetkova, M., Pitson, S. M., and Samuel, M. S. (2018). The Role of the Extracellular Matrix and Its Molecular and Cellular Regulators in Cancer Cell Plasticity. Front Oncol 8, 431.

Ravindran Menon, D., Das, S., Krepler, C., Vultur, A., Rinner, B., Schauer, S., Kashofer, K., Wagner, K., Zhang, G., Bonyadi Rad, E., et al. (2015). A stress-induced early innate response causes multidrug tolerance in melanoma. Oncogene 34, 4448-4459.

Sakaue-Sawano, A., Kurokawa, H., Morimura, T., Hanyu, A., Hama, H., Osawa, H., Kashiwagi, S., Fukami, K., Miyata, T., Miyoshi, H., et al. (2008). Visualizing spatiotemporal dynamics of multicellular cell-cycle progression. Cell 132, 487-498.

Sodek, K. L., Ringuette, M. J., and Brown, T. J. (2009). Compact spheroid formation by ovarian cancer cells is associated with contractile behavior and an invasive phenotype.

International journal of cancer Journal international du cancer 124, 2060-2070.

Spoerri, L., Beaumont, K. A., Anfosso, A., and Haass, N. K. (2017). Real-Time Cell Cycle Imaging in a 3D Cell Culture Model of Melanoma. Methods Mol Biol 1612, 401-416.

Strub, T., Giuliano, S., Ye, T., Bonet, C., Keime, C., Kobi, D., Le Gras, S., Cormont, M., Ballotti, R., Bertolotto, C., and Davidson, I. (2011). Essential role of microphthalmia transcription factor for DNA replication, mitosis and genomic stability in melanoma. Oncogene 30, 2319-2332.

Stylianopoulos, T., Martin, J. D., Chauhan, V. P., Jain, S. R., Diop-Frimpong, B., Bardeesy, N., Smith, B. L., Ferrone, C. R., Hornicek, F. J., Boucher, Y., et al. (2012). Causes, consequences, and remedies for growth-induced solid stress in murine and human tumors. Proceedings of the National Academy of Sciences of the United States of America 109, 15101-15108.

Taubenberger, A., Girardo, S., Träber, N., Fischer-Friedrich, E., Kräter, M., Wagner, K., Kurth, T., Richter, I., Haller, B., Binner, M., et al. (2019). 3D microenvironment stiffness regulates tumor spheroid growth and mechanics via $\mathrm{p} 21$ and ROCK. bioRxiv.

Tsao, H., Chin, L., Garraway, L. A., and Fisher, D. E. (2012). Melanoma: from mutations to medicine. Genes Dev 26, 1131-1155.

Tzanakakis, E. S., Hansen, L. K., and Hu, W. S. (2001). The role of actin filaments and microtubules in hepatocyte spheroid self-assembly. Cell Motil Cytoskeleton 48, 175-189. 
Ullrich, N., Loffek, S., Horn, S., Ennen, M., Sanchez-Del-Campo, L., Zhao, F., Breitenbuecher, F., Davidson, I., Singer, B. B., Schadendorf, D., et al. (2015). MITF is a critical regulator of the carcinoembryonic antigen-related cell adhesion molecule 1 (CEACAM1) in malignant melanoma. Pigment cell \& melanoma research 28, 736-740. Vidal, A., Millard, S. S., Miller, J. P., and Koff, A. (2002). Rho activity can alter the translation of p27 mRNA and is important for RasV12-induced transformation in a manner dependent on p27 status. The Journal of biological chemistry 277, 16433-16440.

Walker, C., Mojares, E., and Del Rio Hernandez, A. (2018). Role of Extracellular Matrix in Development and Cancer Progression. Int J Mol Sci 19.

Yang, S., and Kim, H. M. (2012). The RhoA-ROCK-PTEN pathway as a molecular switch for anchorage dependent cell behavior. Biomaterials 33, 2902-2915.

Yokoyama, S., Woods, S. L., Boyle, G. M., Aoude, L. G., MacGregor, S., Zismann, V., Gartside, M., Cust, A. E., Haq, R., Harland, M., et al. (2011). A novel recurrent mutation in MITF predisposes to familial and sporadic melanoma. Nature 480, 99-103.

Zhang, X., Jiang, G., Cai, Y., Monkley, S. J., Critchley, D. R., and Sheetz, M. P. (2008).

Talin depletion reveals independence of initial cell spreading from integrin activation and traction. Nature cell biology 10, 1062-1068. 


\section{Material and Methods}

\section{Cell lines}

1205Lu-C5, 451Lu-Z1, C8161-A7, WM164-F11, WM793-G10, WM983B-X2, WM983C-Y3 were generated at the Centenary Institute (for a review of correlation functions see Haass et al., 2014) and were made available at the University of Queensland after approved material transfer agreements from all involved parties. All cell lines were genotypically characterized (Davies et al., 2009; Hoek et al., 2006; Smalley et al., 2007a; Smalley et al., 2007b) and authenticated by STR fingerprinting (Analytical Facility, QIMR Berghofer Medical Research Institute, Herston, Australia). None of the cell lines contain the MITF E318K mutation; WM793 and 1205Lu carry the synonymous E388E mutation (pers. comm. Katherine Nathanson, University of Pennsylvania, Philadelphia, PA, USA).

\section{Mice}

Experiments were approved by the University of Sydney Animal Ethics Committee in accordance with the guidelines from the National Health and Medical Research Council (Ethics \#K75/102008/3/4910). CB17 NOD/SCID mice were provided by the Animal Resources Centre, Canning Vale, Australia, and housed in the Centenary Institute Animal Facility, Newtown, Australia.

\section{Plasmids}

The plasmids generated in this paper were made at the University of Queensland and are available after approved material transfer agreement.

\section{Methods}




\section{Cell culture}

All Melanoma-FUCCI cells were cultured in melanoma cell medium: 80\% MCDB-153 medium, 20\% L-15 medium, 4\% fetal bovine serum, $5 \mu \mathrm{g} / \mathrm{mL}$ insulin and $1.68 \mathrm{mM} \mathrm{CaCl} 2$ as per methods published (Spoerri et al., 2017).

a.Generation of MITF knockdown cell lines.

The lentivirus was produced by co-transfection of human embryonic kidney 293T cells with four plasmids, including a packaging defective helper construct (pMDLg/pRRE), a Rev plasmid (pRSV-Rev), a plasmid coding for a heterologous (pCMV-VSV-G) envelope protein, and MISSION® ${ }^{\circledR}$ pLO.1-puro Empty Vector Control Plasmid DNA (PLKO), MISSION® pLKO.1puro Non-Mammalian shRNA Control Plasmid DNA (Scram). The FUCCI-expressing single cell clones WM164-F11, WM983B-X1 and WM983C-Y3 were transduced with MITF MISSION® shRNA Lentiviral Transduction Particles, PLKO or Scram lentivirus, per manufacturer's directions. Transfected cells were selected and cultured in melanoma cell medium containing $1 \mu \mathrm{g} / \mathrm{ml}$ puromycin.

\section{b.Generation of MITF overexpression cell lines}

The open reading frame for the MITF-M was amplified from cDNA generated from A2058 cell line using the primers:

\section{MITF-LVX-Eco-F： 5'-GCGCGAATTCACCATGCTGGAAATGCTAGAA-3' \\ MITF-LVX-Eco-R: $\quad$ 5'-GCGCGAATTCCTAACAAGTGTGCTCCGT-3'}

The primers contained EcoRI restriction sites before the start codon and after the stop codon as well as ACC nucleotides to create an optimal kozac sequence immediately 5 ' to the ATG codon. Insert was cloned into the EcoRI site of the pLVX-PURO vector and the orientation and sequence of the full open reading frame confirmed using $\mathrm{pLVX}$ forward and reverse primers. Lentivirus 
with pLVX-PURO-MITF-M (MITF OE) and with pLVX-PURO vector only (EV) plasmids were generated using Lenti X-HTX packaging system as per manufacturer's instructions.

The FUCCI-expressing single cell clones C8161-A7, WM793b-G10 were transduced with MITFOE or EV lentivirus in $4 \mu \mathrm{g} / \mathrm{ml}$ polybrene. Transfected cells were selected and cultured in melanoma cell medium containing $1 \mu \mathrm{g} / \mathrm{ml}$ puromycin.

Cells were routinely tested for mycoplasma using PCR (Uphoff and Drexler, 2011).

\section{Xenograft studies}

The flanks of 6-week old female CB17 NOD/SCID mice were injected subcutaneously with $2 \times 10^{6}$ FUCCI-transduced melanoma cells in $100 \mu 1$ Melanoma cell medium as previously described (Haass et al., 2008). Mice were weighed thrice weekly and tumor growth measured with digital calipers. Age-matched or size-matched tumors were harvested and compared. Mice were sacrificed when tumors reached $1 \mathrm{~cm}^{3}$ volume or became ulcerated.

Following sacrifice, mice were perfusion fixed by cutting the inferior Vena cava and injecting 10 $\mathrm{ml}$ PBS, followed by $8 \mathrm{ml} 4 \%$ formalin into the left ventricle of the heart. Tumors were surgically excised and placed in $4 \%$ formalin for $18-24 \mathrm{hr}$ at RT. Tumors were cut into $200-\mu \mathrm{m}$ sections using

a vibratome. Sections were placed into ice cold $70 \%$ ethanol for a minimum of $1 \mathrm{~h}$ at $4^{\circ} \mathrm{C}$. For imaging, sections were mounted on glass slides in anti-fade media: $0.25 \%(w / v)$ DABCO and $90 \%$ (v/v) Glycerol $90 \mathrm{ml}$ in PBS) with cover slip held in place using vacuum grease.

\section{Tumor cell clustering image analysis}

Z-stacks of tumor sections were collapsed into an extended focus image. Red and green nucleus masks were created using Volocity software. The coordinates of cell centroids were then exported 
for the clustering analysis (Figure 1C, F). Tumors with large areas of necrosis (no nuclei) were excluded from the analysis.

We adapted the astrophysical correlation function to measure the degree of cell co-location or clustering within a tumor (for a review of correlation functions see Peebles, 1980). The correlation function measures the excess (or diminished) probability, $\mathrm{dP}$, of finding a cell at a distance, $r$, from another cell within some region, $\mathrm{dA}$. It is defined as, $\mathrm{dP}=(1+\quad(\mathrm{r})) \mathrm{N} \mathrm{dA} / \mathrm{A}$, where $\mathrm{N}$ is the number of cells within the area, A.

To explicitly account for the effects of the tumor boundary, the correlation function of green and red cells were measured using the Szalay \& Landy estimator (Landy and Szalay, 1993):

$$
(\mathrm{r})=1+\left\{\left[\left(\mathrm{DD}(\mathrm{r}) /\left(\mathrm{N}_{\mathrm{D}}\left(\mathrm{N}_{\mathrm{D}}-1\right)\right)\right)-\left(\mathrm{DR}(\mathrm{r}) /\left(\mathrm{N}_{\mathrm{D}} \mathrm{N}_{\mathrm{R}}\right)\right)\right] \mathrm{N}_{\mathrm{R}}\left(\mathrm{N}_{\mathrm{R}}-1\right) / \mathrm{RR}(\mathrm{r})\right\} .
$$

It works by comparing the distribution of cell separations to a completely random sample generated by us. $\mathrm{DD}(\mathrm{r}), \mathrm{RR}(\mathrm{r})$ and $\mathrm{DR}(\mathrm{r})$ are the number of unique cell-cell, random-random and cell-random pairs at a separation of $r$. The pair counts were normalized by the total number of cellcell, random-random and cell-random pairs. Random samples were generated with 2-80x density compared to the number of cells in each sample, to ensure that the random sample density is high enough to measure the effect of the tumor boundary on the correlation function. To diminish the effect of an individual random sample on our correlation function measurements, five random samples were generated for each cell sample, and the results were averaged.

The final clustering difference plots were generated in two steps. First, for each tumor image the difference in red and green cell clustering were converted into an absolute difference and then the mean absolute difference for each set of tumor images were calculated. Finally, the mean absolute difference plots were scaled by the standard error of the mean for each tumor set. P-values of 0.05 , 
$0.01,0.005,0.001$ and 0.0001 correspond to sigma values of $1.96,2.58,3.81,3.29$ and 3.89 , in the sigma difference plots.

\section{Spheroid formation}

All spheroids were produced by method described previously (Spoerri et al., 2017). For ROCK inhibitor treatment, spheroids were treated with $10 \mu \mathrm{M}$ Y -27632 at the time of spheroid formation. For hypoxia measurement, spheroids were incubated in $100 \mu \mathrm{M}$ pimonidazole HCL (Hypoxyprobe) for 2 hours at $37^{\circ} \mathrm{C}, 5 \% \mathrm{CO}_{2}$ prior to harvest. On day 4 of the spheroid formation, spheroids were collected for immunofloresence, immunoblots or other following assays.

\section{Spheroid cryosectioning}

Day 4 spheroids were fixed in 4\% paraformaldehyde solution at room temperature for 20 minutes and washed thoroughly in phosphate buffer saline (PBS). The spheroids were then embedded in tissue freezing medium and frozen on dry ice. The molds were then sectioned at $20 \mu \mathrm{m}$ thickness using ThermoFisher HM525NX Cryostat.

\section{Immunostaining}

a. Spheroid section immunostaining

The spheroid sections on glass slides were permeablized using $0.1 \%$ Triton and blocked with 5\% BSA-PBS or ABDIL buffer (Cold Spring Harbor Protocols). The sections were then stained with anti-pimonidazole (1:200, Hypoxyprobe) and the secondary antibody anti-Rabbit IgG-647 (1:1000) in respective blocking buffer with adequate washing with PBS between antibody additions. The sections were stained with 4',6-diamidino-2-phenylindole(DAPI) before being mounted using Mowiol mounting media (Cold Spring Harbor Protocols). The samples were 
imaged using Laser Scanning Confocal Microscope Olympus FV3000: UPlanSApo 10X - NA 0.4, UPlanSApo 20X - NA 075.

b. $2 D$ immunostaining

Cell grown on No.1.5 coverslips were fixed with 1X BRB80 (Cold Spring Harbor Protocols) containing $4 \%$ paraformaldehyde solution at $37^{\circ} \mathrm{C}$ for $12 \mathrm{~min}$, washed in $1 \times \mathrm{xBS}$, permeablized using $0.1 \%$ Triton for 5 min and blocked with ABDIL buffer. The primary antibodies: anti-pFAK (1:200) and anti-pMLC (1:50) and the secondary antibodies: anti-Rabbit IgG-647 (1:1000), antiRabbit IgG-750 (1:1000) were added in ABDIL buffer with adequate washing with TBS-T $(0.1 \%$ Tween) between antibody addition. The samples stained with DAPI, mounted using Mowiol mounting media and imaged using Laser Scanning Confocal Microscope Olympus FV1200: UPlanSApo 60X Oil - NA 1.35. Z-stack images of $1 \mu \mathrm{m}$ thickness were obtained and individual channels were combined to a single image by maximum intensity projection using ImageJ software.

\section{CellProfiler analyses}

a. Percentage of $\mathrm{mKO}^{+}$cells

Spheroids were identified as primary objects using a binary image obtained from the merged mAG and $\mathrm{mKO} 2$ images. $\mathrm{mAG}^{+}$and $\mathrm{mKO}^{+}$cells were identified as primary objects based on their size and their $\mathrm{mAG}$ and $\mathrm{mKO} 2$ signal intensity, then their distance from the spheroid surface measured (minimum child-parent distance). $\mathrm{mAG}^{+}$and $\mathrm{mKO}^{+}$cells were counted in bins of distances from the spheroid surfaces $\left(10 \mu \mathrm{m}\right.$ increments) and the percentage of $\mathrm{mKO}^{+}$cells was calculated for each bin. 
$\%$ of $\mathrm{mKO}^{+}$cells $=\mathrm{mKO} 2+$ cells $/(\mathrm{mKO} 2+$ cells $+\mathrm{mAG}+$ cells $)$

Figure 2: $\mathrm{n}=16\left(\mathrm{WM} 164^{\mathrm{EV}}\right), \mathrm{n}=16\left(\mathrm{WM} 164^{\mathrm{MITF}-\mathrm{KD}}\right), \mathrm{n}=11\left(\mathrm{C} 8161^{\mathrm{EV}}\right), \mathrm{n}=12\left(\mathrm{C} 8161^{\mathrm{MITF}-\mathrm{OE}}\right)$.

Figure 2S: $\mathrm{n}=7$ Figure 2S: $\left(\mathrm{WM} 983 \mathrm{~B}^{\mathrm{EV}}\right), \mathrm{n}=7\left(\mathrm{WM} \mathrm{M} 3 \mathrm{~B}^{\mathrm{MITF}-\mathrm{KD}}\right), \mathrm{n}=8\left(\mathrm{WM} 793 \mathrm{~B}^{\mathrm{EV}}\right), \mathrm{n}=7$ $\left(\mathrm{WM} 793 \mathrm{~B}^{\mathrm{MITF}-\mathrm{OE}}\right)$.

Figure 8: $\mathrm{n}=6\left(\mathrm{C} 8161^{\mathrm{EV}}\right), \mathrm{n}=6\left(\mathrm{C} 8161^{\mathrm{MITF}-\mathrm{OE}}\right), \mathrm{n}=6\left(\mathrm{C} 8161^{\mathrm{EV}+\mathrm{Y}}\right), \mathrm{n}=6\left(\mathrm{WM} 164^{\mathrm{EV}}\right), \mathrm{n}=6$ $\left(\mathrm{WM} 164^{\mathrm{MITF}-\mathrm{KD}}\right), \mathrm{n}=9\left(\mathrm{WM} 164^{\mathrm{MITF}-\mathrm{KD}+\mathrm{Y}}\right)$.

Data: mean \pm SEM; analysis: two-way ANOVA for the effect of MITF on $\%$ of $\mathrm{mKO} 2+$ cells

b. Percentage of $\mathrm{Pim}^{+}$cells

Spheroids were identified as primary objects using a binary image obtained from the merged mAG and $\mathrm{mKO} 2$ images. DAPI images were used to identify cell nuclei as primary objects and to measure cell distance from the spheroid surface (minimum child-parent distance). Signal intensity of secondary objects based on Pim images was used to identify $\mathrm{Pim}^{+}$cells. $\mathrm{Pim}^{+}$cells were counted in bins of distances from the spheroid surfaces $(10 \mu \mathrm{m}$ increments $)$ and the percentage of $\mathrm{Pim}^{+}$cells out of the sum of the total cell number (cell nuclei) calculated for each bin.

$\%$ of $\mathrm{Pim}^{+}$cells $=\mathrm{Pim}^{+}$cells $/ \mathrm{DAPI}^{+}$cells

Figure 3: $\mathrm{n}=5\left(\mathrm{C} 8161^{\mathrm{EV}}\right), \mathrm{n}=4\left(\mathrm{C} 8161^{\mathrm{MITF}-\mathrm{OE}}\right), \mathrm{n}=4\left(\mathrm{WM} 164^{\mathrm{EV}}\right), \mathrm{n}=3\left(\mathrm{WM} 164^{\mathrm{MITF}-\mathrm{KD}}\right)$.

Figure 3S: $n=3\left(\mathrm{WM} 793 \mathrm{~B}^{\mathrm{EV}}\right), \mathrm{n}=3\left(\mathrm{WM} 793 \mathrm{~B}^{\mathrm{MITF}-\mathrm{OE}}\right)$.

Data: mean $\pm S E M$; analysis: two-way ANOVA for the effect of MITF on $\%$ of $\mathrm{Pim}^{+}$cells

c. Mean intensity of $p M L C 2$

DAPI images were used to identify cell nuclei as primary objects while secondary objects were identified based on pMLC2 images. Mean intensity pMLC2 signal was measured for each cell based on identified secondary objects; $\mathrm{n}=58\left(\mathrm{C} 8161^{\mathrm{EV}}\right), \mathrm{n}=62\left(\mathrm{C} 8161^{\mathrm{MITF-OE}}\right), \mathrm{n}=60$ 
$\left(\mathrm{WM} 164^{\mathrm{EV}}\right), \mathrm{n}=73\left(\mathrm{WM} 164^{\mathrm{MITF}-\mathrm{KD}}\right)$ cells from 3 independent experiments; analysis: Student $\mathrm{t}-$ test.

\section{d. Focal adhesion eccentricity}

Focal adhesions were identified as primary objects based on their size and pFAK signal, then their count and shape eccentricity (referred to as elongation) was calculated. Considering each focal adhesion an ellipse, the eccentricity is the ratio of the distance between the foci of the ellipse and its major axis length. The value is between 0 and $1(0=$ circle, $1=$ line segment $) ; \mathrm{n}=44\left(\mathrm{C} 8161^{\mathrm{EV}}\right)$, $\mathrm{n}=53\left(\mathrm{C} 8161^{\mathrm{MITF}-\mathrm{OE}}\right), \mathrm{n}=62\left(\mathrm{WM} 164^{\mathrm{EV}}\right), \mathrm{n}=64\left(\mathrm{WM} 164^{\mathrm{MITF}-\mathrm{KD}}\right)$ cells from 3 independent experiments; analysis: Student t-test.

e. Elongated focal adhesion count

The number of properly formed elongated focal adhesions per cell were manually counted. Phosphorylated FAK signal that had defined edges were included in the count. $n=48\left(\mathrm{C} 8161^{\mathrm{EV}}\right)$, $\mathrm{n}=53\left(\mathrm{C} 8161^{\mathrm{MITF}-\mathrm{OE}}\right), \mathrm{n}=59\left(\mathrm{WM} 164^{\mathrm{EV}}\right), \mathrm{n}=65\left(\mathrm{WM} 164^{\mathrm{MITF}-\mathrm{KD}}\right)$ cells from 3 independent experiments; analysis: Student t-test.

\section{SPIM}

Day4 spheroids were mounted in imaging chamber (Favre-Bulle et al., 2018) using 1.5\% low melting agarose and submerged in PBS. The submerged spheroids were then imaged using a diffused digitally scanned light-sheet microscope (Taylor et al., 2018) with two light-sheets illuminating the sample. The scanning light sheet was generated using a 488nm laser (OBIS 488 1x), attenuated with a ND filter (Thorlabs NE10A), scanned with 2D galvo mirrors (Thorlabs GVSM002/M), a 50/50 beamsplitter, and a 1D line diffuser (RPC Photonics EDL-20-07337). One 
galvo scanning direction $(\mathrm{Y})$ created the light sheet while the second direction $(\mathrm{Z})$ created the depth scan in the sample. The two mirrors were driven independently using Arduinos (DUE) with custom-written code. The Y scanning was a sawtooth scan at $600 \mathrm{~Hz}$, which was synchronized to the camera acquisition to ensure similar illumination for each camera acquisition. The $\mathrm{Z}$ galvo was driven in steps to scan the light-sheet through the sample. The 50/50 beamsplitter created two light sheets projecting orthogonally in the sample. Excitation was gathered by an Olympus Plan N 10x 0.25 NA objective and projected onto the PCO edge 5.5 camera with a combination of filter (F, Thorlabs FF01-517/520-25), tube lens (L3, $180 \mathrm{~mm}$ focal length, Thorlabs AC508-180-A), relay lenses (Lr, Thorlabs AC254-125-A-ML), ETL (Optotune EL-10-30-Ci-VIS-LD driven with Gardasoft TR-CL180) and offset lens (Lo, Eksma Optics 112-0127E). SPIM: objective information, section thickness, any post processing

The imaging system was controlled using $\mu$ Manager, based on ImageJ (Edelstein et al., 2010; Taylor et al., 2018). The exposure time was set at 100ms for each plane, with a laser power output of $40 \mathrm{~mW}$, which was attenuated to $1 \mathrm{~mW}$ for each plane at the sample. The depth of scanning was adapted to each spheroid with $3 \mu \mathrm{m}$ steps between each plane.

In our experiments, an exposure time of $10 \mathrm{~ms}$ was chosen for each plane during volumetric imaging, with laser power output of $40 \mathrm{~mW}$, which was attenuated to $1.5 \mathrm{~mW}$ for each plane at the sample.

Three-dimensional image reconstruction and the equatorial and polar diameter measurements were done using imageJ software. Spheroid roundness was calculated by polar diameter/ equatorial diameter; $\mathrm{n}=3$.

\section{Immunoblot}


Cells from $80 \%$ confluent flask or 4 day old spheroids were lysed in RIPA lysis buffer: $150 \mathrm{mM}$ $\mathrm{NaCl}, 5 \mathrm{mM}$ EDTA (pH 8.0), 50mM Tris (pH 8.8), 1\% (v/v) NP-40 (IGEPAL CA-630), 0.5\% (w/v) Sodium deoxycholate and $0.1 \%$ (w/v) SDS, quantified using Pierce ${ }^{\mathrm{TM}}$ BCA Protein Assay Kit and boiled in sample buffer: $30 \%(\mathrm{v} / \mathrm{v})$ glycerol, $60 \mathrm{mM}$ Tris, $2 \%(\mathrm{w} / \mathrm{v})$ SDS, $10 \%(\mathrm{v} / \mathrm{v}) \beta-$ mercaptoethanol, $0.1 \%(\mathrm{w} / \mathrm{v})$ bromophenol blue. Alternatively, the cells were lysed directly in sample buffer containing 50mM Tris (pH6.8), 3\% (w/v) SDS, 10\% (v/v) glycerol, 100mM DTT and $0.1 \%(\mathrm{w} / \mathrm{v})$ bromophenol blue and sonicated. All buffers contained 1x protease inhibitor cocktail, $1 \mathrm{mM}$ phenylmethylsulfonyl fluoride, $1 \mathrm{mM}$ sodium orthovanadate, $1 \mathrm{mM}$ Sodium fluoride, $1 \mathrm{ug} / \mathrm{ml}$ Aprotinin and $1 \mathrm{ug} / \mathrm{ml}$ Leupeptin at the time of lysis and were boiled for $5 \mathrm{~min}$ at $95^{\circ} \mathrm{C}$ prior to use. Approximately $20-30 \mu$ g protein was loaded per lane on NuPAGETM $4-12 \%$ BisTris Protein Gels and electro-blotted on to Immobilon-P PVDF Membrane [FIG1] or on 10\% BisTris gel and electro-blotted on to Immun-Blot ${ }^{\circledR}$ Low Fluorescence PVDF membrane [FIG2]. Membranes were blocked in 5\% skim milk in TBS-T $(0.1 \%$ tween) and probed with antibodies against: MITF (1:500), Rab27a (1:1000), GAPDH (1:5000). Following washes with TBS-T, bound antibodies were detected with anti-mouse IgG-HRP or anti-rabbit IgG-HRP (1:500) and Clarity ${ }^{\mathrm{TM}}$ Western ECL Substrate. The intensity of the bands were measured using imageJ and normalized to GAPDH before fold change difference was calculated.

\section{Flow cytometry for FUCCI}

Cells were seeded on tissue culture plastic in melanoma cell medium at 40,000 cells $/ \mathrm{cm}^{2}$ for 24 hours, dissociated using trypsin and analyzed using Flow Analyser LSR Fortessa X20. The number of $\mathrm{mKO}^{+}$and $\mathrm{mAG}^{+}$cells were calculated based on histogram and the $\% \mathrm{mKO}^{+}$cells were calculated. 
$\%$ of $\mathrm{mKO}^{+}$cells $=\mathrm{mKO} 2+$ cells $/(\mathrm{mKO} 2+$ cells $+\mathrm{mAG}+$ cells $)$

$\mathrm{N}=3$ independent experiments; analysis: two-way ANOVA on \% of mKO2+ cells.

\section{Spheroid cell count}

Approximately 90-96 day-4 spheroids were dissociated using trypsin and 6 independent samples were counted from the pool using Countess II FL Automated Cell Counter. The averaged cell count was normalized to the number of spheroids counted. $\mathrm{N}=3$ independent experiments; analysis: student t-test.

\section{Proteomics}

Cells were seeded on tissue culture plastic in melanoma cell medium at 40,000 cells $/ \mathrm{cm}^{2}$ for 24 hours (2D) or 4-day old spheroids (3D) were used. The samples were washed in thoroughly in PBS, lysed in buffer containing 1\% Sodium deoxycholate, 10mM tris(2-carboxyethyl)phosphine (TCEP), 40mM 2-chloroacetamide, 1x Protease inhibitor cocktail in 100mM Tris(pH 8) and sonicated at $4^{\circ} \mathrm{C}$ for $15 \mathrm{~min}$ in a water bath sonicator. The samples were clarified by centrifugation at $13000 \mathrm{x} \mathrm{g}, 4^{\circ} \mathrm{C}$ for $10 \mathrm{~min}$. The supernatant was collected and the protein concentration was measured using direct detect. Protein samples of $10 \mathrm{ug}$ were denatured at $1 \mathrm{ug} / \mathrm{ul}$ by boiling for 5 min at $95^{\circ} \mathrm{C}$. The samples were diluted 1 in 10 with water before overnight digest with 0.2 ug of trypsin at $37^{\circ} \mathrm{C}$. Samples were acidified with $0.5 \%(\mathrm{v} / \mathrm{v})$ trifluoro acetic acid and centrifuged at $13000 \mathrm{x} \mathrm{g}$ for $10 \mathrm{~min}$. The supernatant was purified using Glygen C18 tips before being analyzed on Thermo Scientific Easy nLC 1000 with Q Exactive Plus orbitrap mass spectrometer. Peptides were loaded onto a 2mm x75um c18 trap column and separated with an Easy LC C18 analytical column $50 \mathrm{~cm} \times 50 \mathrm{um}$ over $100 \mathrm{mins}$ from $3 \%$ to $25 \%$ acetonitrile in $0.1 \%$ formic acid, followed 
by 40 mins from $25 \%$ to $40 \%$ acetonitrile. Mass spectrum was acquired at $70 \mathrm{~K}$ resolution, 350 $1400 \mathrm{~m} / \mathrm{z}, 3 \mathrm{e} 6 \mathrm{AGC}$ with a maximum injection time of $100 \mathrm{~ms}$ and data dependent ms 2 was acquired at $17.5 \mathrm{~K}$ resolution, $5 \mathrm{e} 5 \mathrm{AGC}$ maximum injection time of $55 \mathrm{~ms}$, TopN of 20 , dynamic exclusion of $30 \mathrm{~s}$ and exclusion of unassigned, 1, 8 and $>8 \mathrm{z}$. Mass spectrum data was searched against from Swiss-Prot - human species protein database (April 2017) using Spectrum Mill and Proteome Discoverer search engines with standard setting of tryptic peptides with a maximum of 2 miscleavages, fixed carbamidomethylated cysteine and variable oxidation of methionine. Only proteins with FDR of $<1 \%$ were use in subsequent analysis. Filtering was performed for proteins reliably detected in 3 out of 4 technical replicates of at least one of the experimental groups. The

analysis was performed by Queensland Cyber Infrastructure Foundation Ltd, The University of Queensland - St Lucia, QLD-4072. Additional filtering was performed for proteins reliably detected in all 4 technical replicates of at least one of the experimental groups. After filtering 2657 proteins remained. Differential proteins were determined by Analysis of variance (ANOVA) with correction for multiple testing uses the False Discovery Rate method from Benjamini and Hochberg. All analyses were carried out using the R statistical software (R Core Team, 2013).

Functional enrichment analysis of the differentially expressed proteins was performed using the STRING biological database and web resource based on the Genet Ontology (GO) functional classification system with default settings on $18^{\text {th }}$ of May 2020 .

\section{Individual cell imaging in spheroids}

Cells were stained with $10 \mu \mathrm{M}$ CellTracker ${ }^{\mathrm{TM}}$ Deep Red Dye as per manufacturer's protocol and mixed with unstained cells at 1:50 ratio respectively before spheroid formation. The spheroids were treated with $10 \mu \mathrm{M}$ Y-27632 every day for treatment condition. On day 4, spheroids were 
fixed and cleared using CUBIC based method as described previously (Lloyd-Lewis et al., 2016). The spheroids were incubated in 50\% (v/v) CUBIC Reagent $1 \mathrm{~A}$ at room temperature for $1 \mathrm{hr}$ and then in $100 \% \mathrm{CUBIC}$ reagent $1 \mathrm{~A}$ at $37^{\circ} \mathrm{C}$ for $6-8 \mathrm{hr}$ till the spheroids were transparent. They were then mounted in CUBIC Reagent 2 overnight for refractive index matching. Images were acquired using Laser Scanning Confocal Microscope Olympus FV3000: UPlanFL N 40X Oil - NA 1.3. Zstack images of $1 \mu \mathrm{m}$ thickness were obtained and images of CellTracker ${ }^{\mathrm{TM}}$ stained cells were temporally color coded and stacked for observation using ImageJ software.

\section{Accumulated solid stress analysis in spheroids}

Manual incisions were made using an 11 blade on day 4 spheroids ranging between $35-55 \%$ of the spheroid diameter and imaged using Inverted Manual Microscope Olympus IX73: UPlanFL N 10x

- NA 0.30. The spheroid diameter (d), incision depth (i), and the opening distance (a) were measured using ImageJ software. The relaxation indices (RI) were calculated using the formula: $\mathrm{RI}=\mathrm{a} / \mathrm{d} * 100$. Experiments were repeated three times with multiple technical replicates and statistical significance calculated using the Student t-test in GraphPad Prism.

\section{Collagen contraction assay}

Collagen solution of $2 \mathrm{mg} / \mathrm{ml}$ was made using $40 \%(\mathrm{v} / \mathrm{v})$ bovine type 1 collagen, $10 \%(\mathrm{v} / \mathrm{v}) 10 \mathrm{x}$ EMEM, 1\% (v/v) GlutaMAX ${ }^{\mathrm{TM}}, 2 \%(\mathrm{v} / \mathrm{v})$ Sodium bicarbonate and 10\% (v/v) fetal bovine serum. The working stock of cell suspension was made in melanoma cell medium at $2 \times 10^{5}$ cells $/ \mathrm{ml}$. The two solutions were mixed 1:1 and $500 \mu 1$ of solution was added per well of 24 well plate and incubated at $37^{\circ} \mathrm{C}$ immediately for 30 minutes. Once the gel solidified, $1.5 \mathrm{ml}$ medium per well was added with or without $10 \mu \mathrm{M}$ Y-27632. The plates were imaged on day 4 using Bio-Rad 
ChemiDoc MP to obtain a quick snapshot of the whole plate and the area of the plugs were measured using ImageJ. The percentage of contraction was calculated in relation to acellular plugs. Matrix plug area $=$ area of cell treated collagen plug / area of acellular collagen plug

Experiments were repeated three times for statistical significance and analyzed using paired student t-test.

\section{References}

Davies, M. A., Stemke-Hale, K., Lin, E., Tellez, C., Deng, W., Gopal, Y. N., Woodman, S. E., Calderone, T. C., Ju, Z., Lazar, A. J., et al. (2009). Integrated Molecular and Clinical Analysis of AKT Activation in Metastatic Melanoma. Clin Cancer Res 15, 7538-7546.

Edelstein, A., Amodaj, N., Hoover, K., Vale, R., and Stuurman, N. (2010). Computer control of microscopes using microManager. Curr Protoc Mol Biol Chapter 14, Unit14 20.

Favre-Bulle, I. A., Vanwalleghem, G., Taylor, M. A., Rubinsztein-Dunlop, H., and Scott, E. K. (2018). CellularResolution Imaging of Vestibular Processing across the Larval Zebrafish Brain. Current biology : CB 28, 3711-3722 e3713.

Haass, N. K., Beaumont, K. A., Hill, D. S., Anfosso, A., Mrass, P., Munoz, M. A., Kinjyo, I., and Weninger, W. (2014). Real-time cell cycle imaging during melanoma growth, invasion, and drug response. Pigment Cell Melanoma Res 27, 764-776.

Haass, N. K., Sproesser, K., Nguyen, T. K., Contractor, R., Medina, C. A., Nathanson, K. L., Herlyn, M., and Smalley, K. S. (2008). The mitogen-activated protein/extracellular signal-regulated kinase kinase inhibitor AZD6244 (ARRY-142886) induces growth arrest in melanoma cells and tumor regression when combined with docetaxel. Clin Cancer Res 14, 230-239.

Hoek, K. S., Schlegel, N. C., Brafford, P., Sucker, A., Ugurel, S., Kumar, R., Weber, B. L., Nathanson, K. L., Phillips, D. J., Herlyn, M., et al. (2006). Metastatic potential of melanomas defined by specific gene expression profiles with no BRAF signature. Pigment Cell Res 19, 290-302.

Landy, S. D., and Szalay, A. S. (1993). Bias and variance of angular correlation functions. Astrophys J 412, 64-71.

Lloyd-Lewis, B., Davis, F. M., Harris, O. B., Hitchcock, J. R., Lourenco, F. C., Pasche, M., and Watson, C. J. (2016). Imaging the mammary gland and mammary tumours in $3 \mathrm{D}$ : optical tissue clearing and immunofluorescence methods. Breast cancer research : BCR 18, 127.

Peebles, P. J. E. (1980). Large-Scale Structure of the Universe: Princeton University Press).

R Core Team (2013). A language and environment for statistical computing. In, (R Foundation for Statistical Computing, Vienna, Austria.).

Smalley, K. S., Contractor, R., Haass, N. K., Kulp, A. N., Atilla-Gokcumen, G. E., Williams, D. S., Bregman, H., Flaherty, K. T., Soengas, M. S., Meggers, E., and Herlyn, M. (2007a). An organometallic protein kinase inhibitor pharmacologically activates p53 and induces apoptosis in human melanoma cells. Cancer Res 67, 209-217.

Smalley, K. S., Contractor, R., Haass, N. K., Lee, J. T., Nathanson, K. L., Medina, C. A., Flaherty, K. T., and Herlyn, M. (2007b). Ki67 expression levels are a better marker of reduced melanoma growth following MEK inhibitor treatment than phospho-ERK levels. Br J Cancer 96, 445-449. 
Spoerri, L., Beaumont, K. A., Anfosso, A., and Haass, N. K. (2017). Real-Time Cell Cycle Imaging in a 3D Cell Culture Model of Melanoma. Methods Mol Biol 1612, 401-416.

Taylor, M. A., Vanwalleghem, G. C., Favre-Bulle, I. A., and Scott, E. K. (2018). Diffuse light-sheet microscopy for stripe-free calcium imaging of neural populations. J Biophotonics 11, e201800088.

Uphoff, C. C., and Drexler, H. G. (2011). Detecting mycoplasma contamination in cell cultures by polymerase chain reaction. Methods in molecular biology 731, 93-103. 


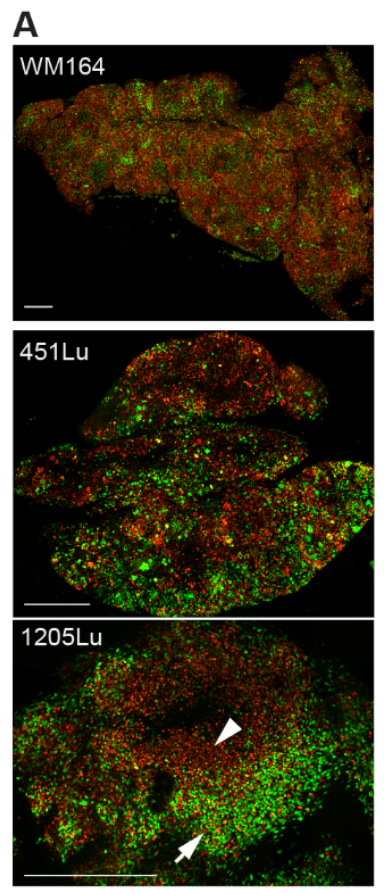

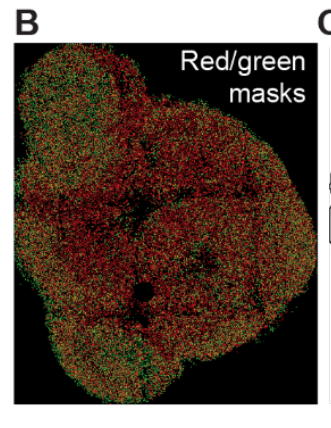

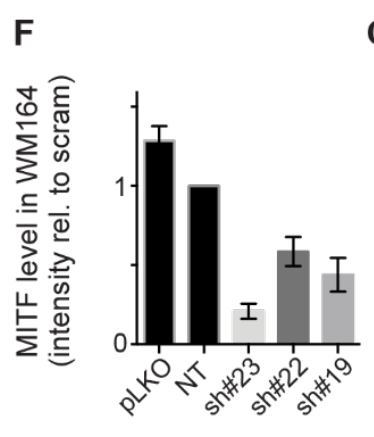

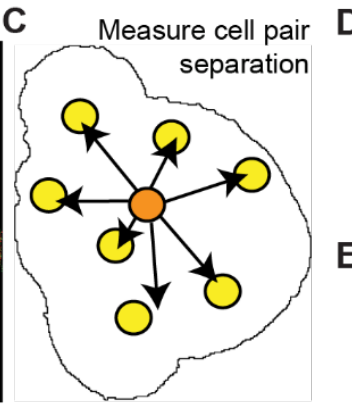

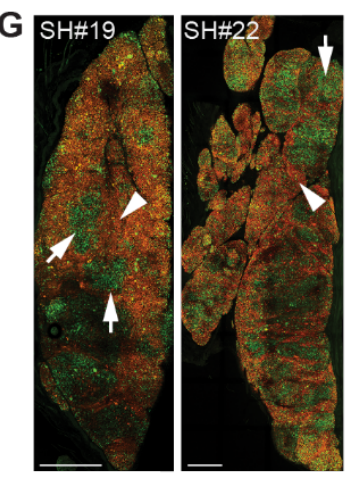

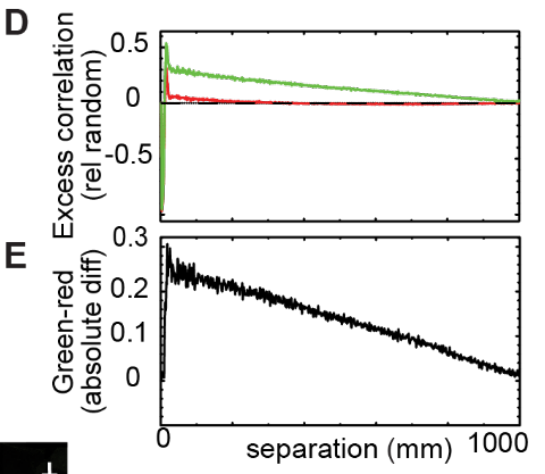

H

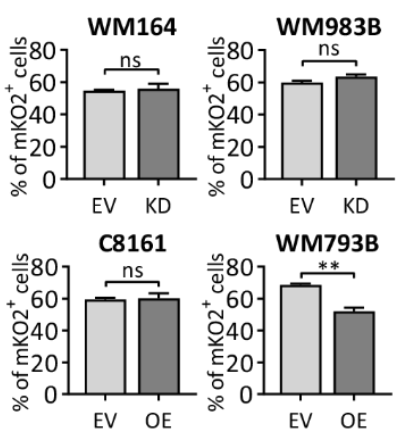

Figure S1: Phenotypic heterogeneity in melanoma xenograft tumors in vivo is dependent on expression levels of MITF, clustering analysis method, MITF expression levels in WM164 cells and percentage of $\mathrm{mKO}^{+}$cells in adherent cultures. (A) Representative examples of predominantly homogeneously proliferating MITF $^{\text {high }}$ (WM164 and 451Lu) and clustered MITF ${ }^{\text {low }}(1205 \mathrm{Lu})$ xenografts. Arrows and arrowheads indicate proliferating and $\mathrm{G}_{1}$ arrested clusters, respectively; scale bars: $0.5 \mathrm{~mm}$. (B) Clustering analysis method using Figure 1B (low MITF, C8161) as an example. Red/green nuclei masks (centroids) automatically generated in Volocity. Note that not all cells could be separated due to the high density - but the overall red/green cell pattern matches the original image (Figure 1B). (C) The distance of each green cell to every other green cell in the image was measured; the same process was repeated for the red cells. (D) A random sample was generated within the tumor border. Histograms of red-red, red-random, green-green, green-random and random-random pair separations were combined to measure the excess/diminished red-red and green-green pairs at a given separation, while taking into account the tumor border. Note that for this image there is an accumulation of green cell pairs (relative to the random sample - dotted line) separated 
by shorter distances. This indicates that the green cells are showing increased clustering at these distances. (E) To combine the analyses of multiple tumors, we used the mean of the absolute differences between the green and red excess correlation curves. We identified differences in red and green clustering irrespective of which was stronger. Here we show the absolute difference curve for this particular tumor. (F) MITF expression level measured by Western Blot of WM164 cells expressing vector only (PLKO), scrambled shRNA (scram) and three different shRNA targeting MITF (sh\#23, sh\#22 and sh\#19). (G) Representative examples of clustered xenografts generated with MITF-depleted cells (sh\#19 and sh\#22). Arrows and arrowheads indicate proliferating and $\mathrm{G}_{1}$-arrested clusters, respectively; scale bars: $1 \mathrm{~mm}$. (H) Percentage of $\mathrm{mKO}^{+}$cells $\left(\mathrm{mKO}^{+}\right.$cells $/\left(\mathrm{mKO}^{+}\right.$cells $+\mathrm{mAG}^{+}$cells $\left.)\right)$in adherent cultures of WM164, WM983B, C8161 and WM793B; parental (PAR), SCR (scrambled shRNA), EV (empty vector), KD (MITF knock down) and OE (MITF overexpression). 

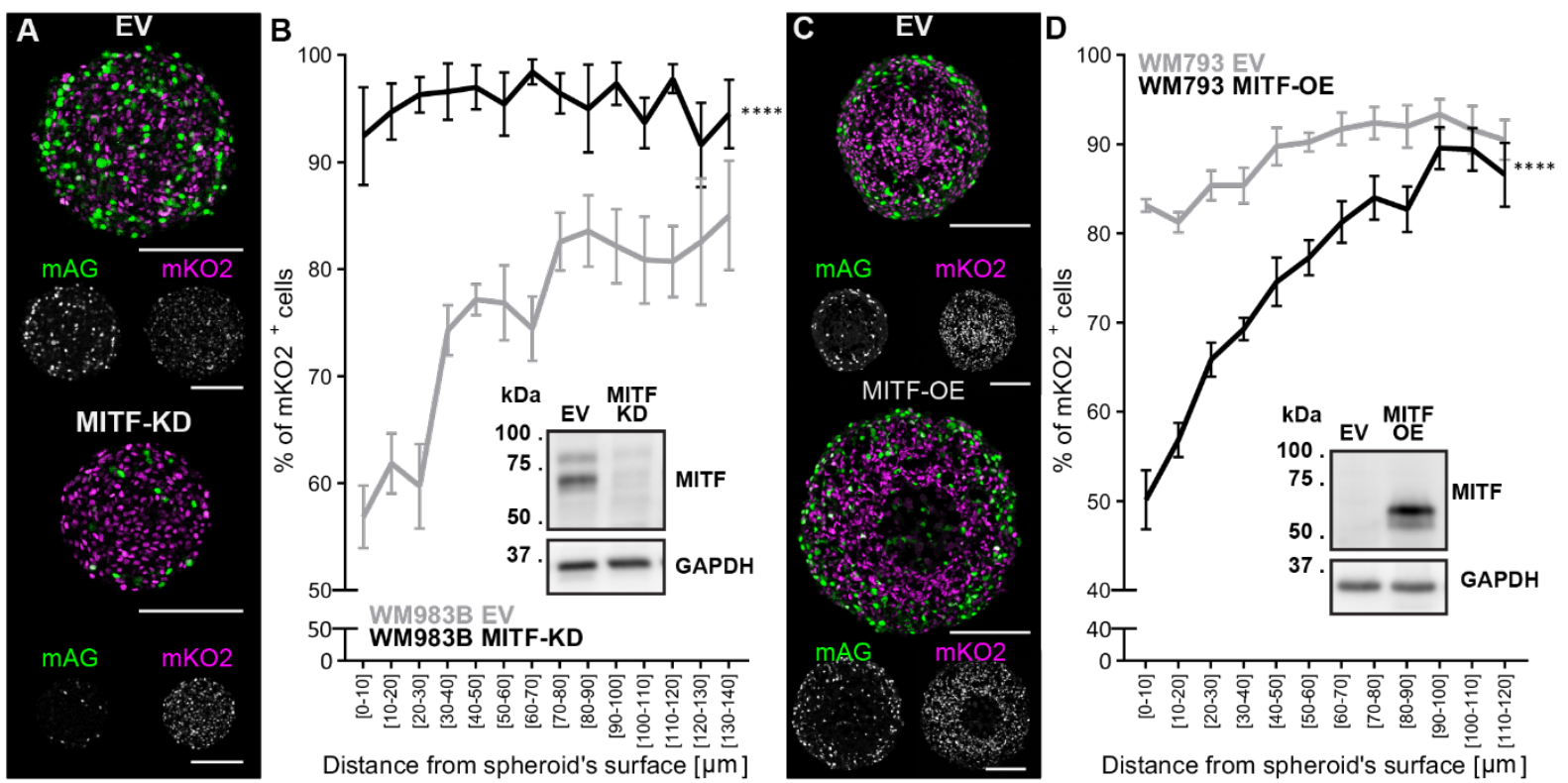

Figure S2: Phenotypic heterogeneity in melanoma xenograft tumors in vitro is dependent

on expression levels of MITF. (A,C) Representative FUCCI fluorescence images (monomeric Azami green, mAG, green; monomeric Kusabira Orange2, mKO2, magenta) of equatorial cryosections of spheroids with MITF depleted $\left(\right.$ WM983B ${ }^{\text {MITF-KD }}$ ) or overexpressed $\left(\mathrm{WM} 793 \mathrm{~B}^{\mathrm{MITF}-\mathrm{OE}}\right)$, and the respective controls $\left(\mathrm{WM} 983 \mathrm{~B}^{\mathrm{EV}}\right.$ and $\mathrm{WM} 793 \mathrm{~B}^{\mathrm{EV}}$ ). Areas of $\mathrm{mAG}^{+}$ and $\mathrm{mKO}^{+}$cells proliferate, while zones enriched with $\mathrm{mKO} 2^{+}$cells are $\mathrm{G}_{1}$-arrested; scale bars: $200 \mu \mathrm{m}$. (B,D) Analysis of $\mathrm{G}_{1}$-arrest spatial distribution. Graphs show the percentage of $\mathrm{mKO}^{+}$cells $\left(\mathrm{mKO}^{+}\right.$cells $/\left(\mathrm{mKO}^{+}\right.$cells $+\mathrm{mAG}^{+}$cells $\left.)\right)$as a function of distance from the spheroid surface. Note, cells beyond specific spheroid depths (cell-line dependent) were omitted from the analysis because of high variability driven by core necrosis. WM983B: $\mathrm{n}=7$ (EV), n=7 (MITF-KD); WM793B: n=8 (EV), n=7 (MITF-OE); data: mean \pm SEM; analysis: two-way ANOVA for the effect of MITF on $\%$ of $\mathrm{mKO}^{+}$cells; $* * * * p<0.0001$. Immunoblots show the level of MITF knockdown (B) and overexpression (D). EV, empty vector; KD, knockdown; OE, overexpression. 

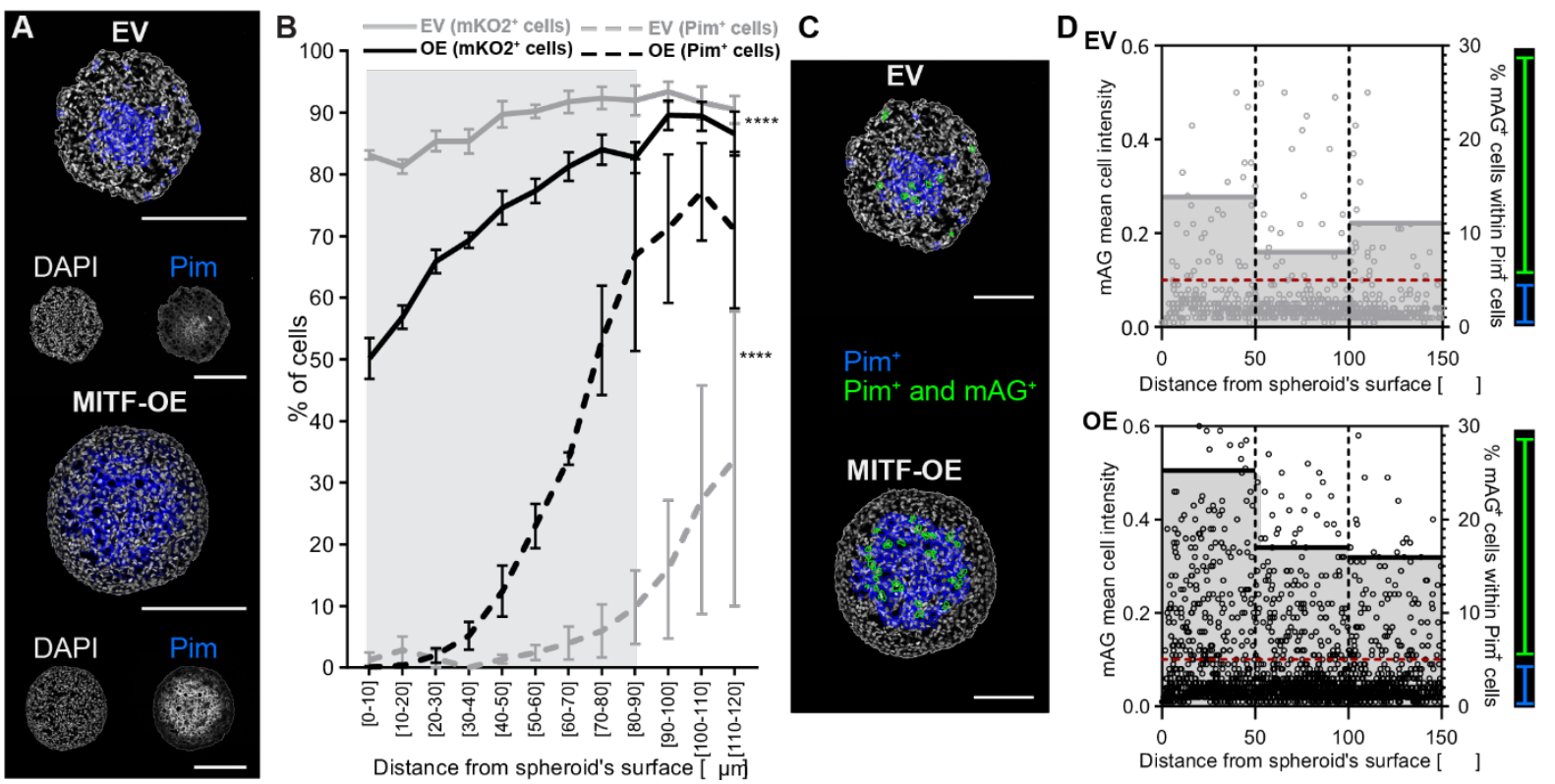

Figure S3: High MITF levels allow proliferation of melanoma cells in hypoxia. (A)

Representative fluorescence (DAPI and pimonidazole) images of equatorial cryosections of WM793B ${ }^{E V}$ and WM793B ${ }^{M I T F-O E}$ spheroids; scale bars: $200 \mu \mathrm{m}$. (B) Analysis of spatial distribution of hypoxic cells (pimonidazole-positive, Pim $^{+}$) within spheroids. Graphs show the percentage of $\mathrm{Pim}^{+}$cells $\left(\mathrm{Pim}^{+}\right.$cells/DAPI cells) as a function of radial distance from the spheroid surface (dashed curves). Gray shading, distance range from spheroid surface where percentage of the $\mathrm{KKO}^{+}$cells diverges between EV and MITF-OE cohorts, based on data shown in Fig. S2D (solid curves); data: mean $\pm S E M$; analysis=two-way ANOVA for the effect of MITF on \% of Pim ${ }^{+}$cells; $n$.s. $p>0.05$. (C) CellProfiler generated mask overlaid on DAPI image, showing Pim + cells outline (blue) and Pim + and $m A G+$ (green). (D) Dot plot of $m A G$ mean fluorescence intensity (read on left y axis) of each Pim ${ }^{+}$cell of all analyzed spheroids as a function of distance from the spheroid surface. Grey shaded bars, percentage of Pim ${ }^{+} / \mathrm{mAG}^{+}$ (hypoxic and cycling) cells in each distance bin (read on right y axis). Horizontal red dotted line, threshold for $m A G$ positivity. 

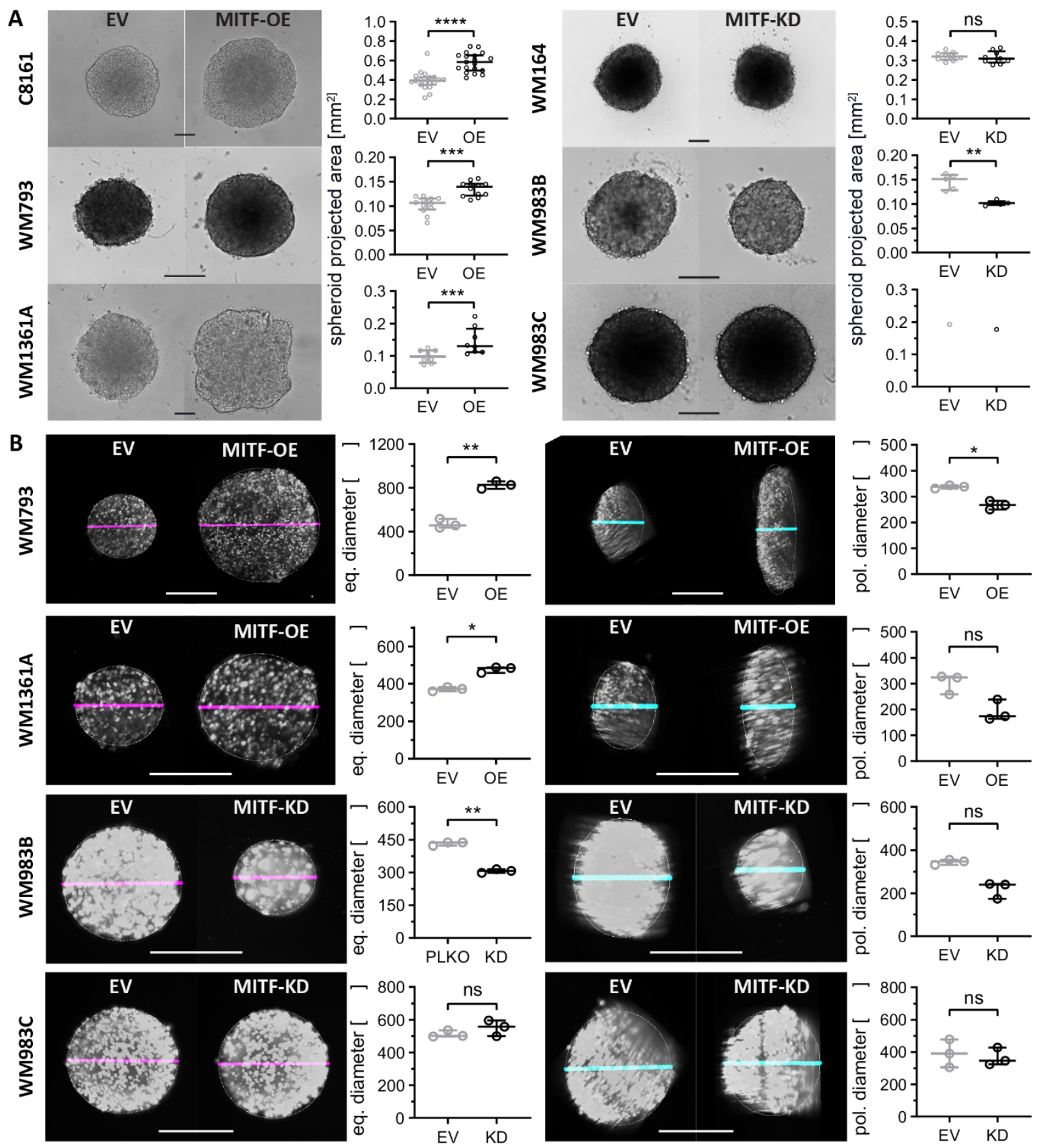

\section{C}

WM793B

WM1361A

WM164

WM983B

WM983C
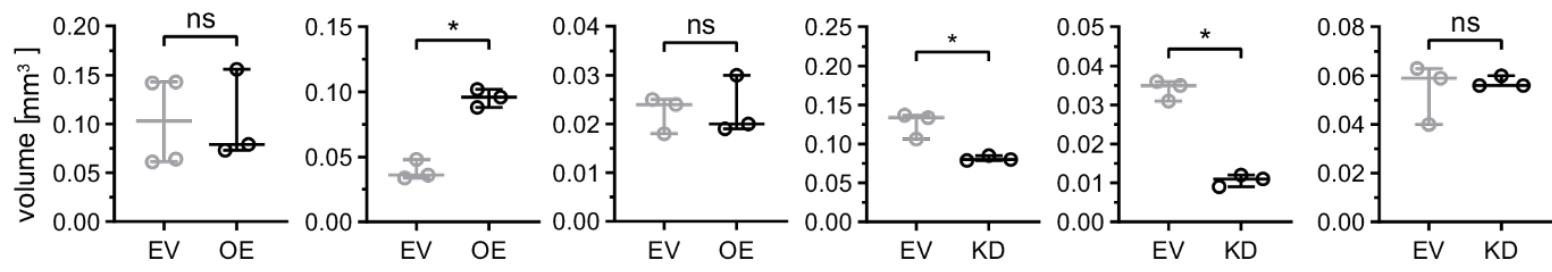

D

C8161

WM793B
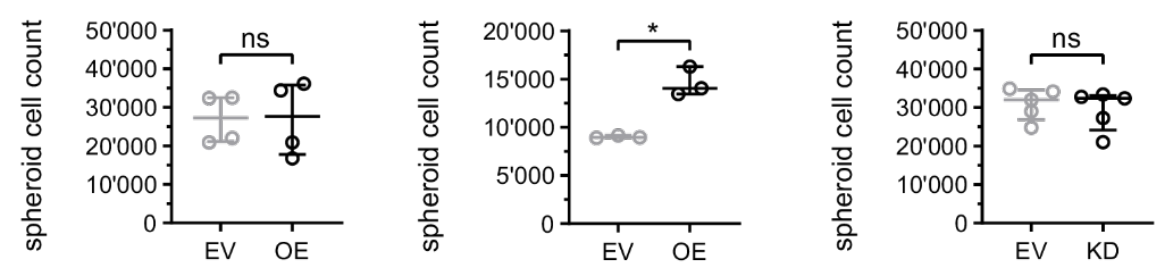

WM983B 
Figure S4: Spheroid morphology and cell count (A) Representative bright-field microscopy images of spheroids and quantitation of their projected areas. (B) Representative SPIM images (utilizing $\mathrm{mAG}$ for fluorescence) and quantitation of polar and equatorial diameters of live WM793B $\mathrm{B}^{\text {EV/MITF-OE }}, \mathrm{WM} 1361 \mathrm{~A}^{\text {EV/MITF-OE }}, \mathrm{WM} 983 \mathrm{~B}^{\text {EV/MITF-KD }}$ and $\mathrm{WM} 983 \mathrm{C}^{\text {EV/MITF-KD }}$ spheroids. Magenta and cyan lines indicate measured equatorial and polar diameters, respectively, scale bars: $200 \mu \mathrm{m}$. (C) Spheroid volume calculated based on the measured equatorial and polar diameters. (D) Spheroids were dissociated and cells counted. Scatter dot plot of median and interquartile range; analysis: Student t-test, $* * * * p<0.0001, * * * p<0.001, * *$ $\mathrm{p}<0.01,{ }^{*} \mathrm{p}<0.05$, n.s. $\mathrm{p}>0.05$. 


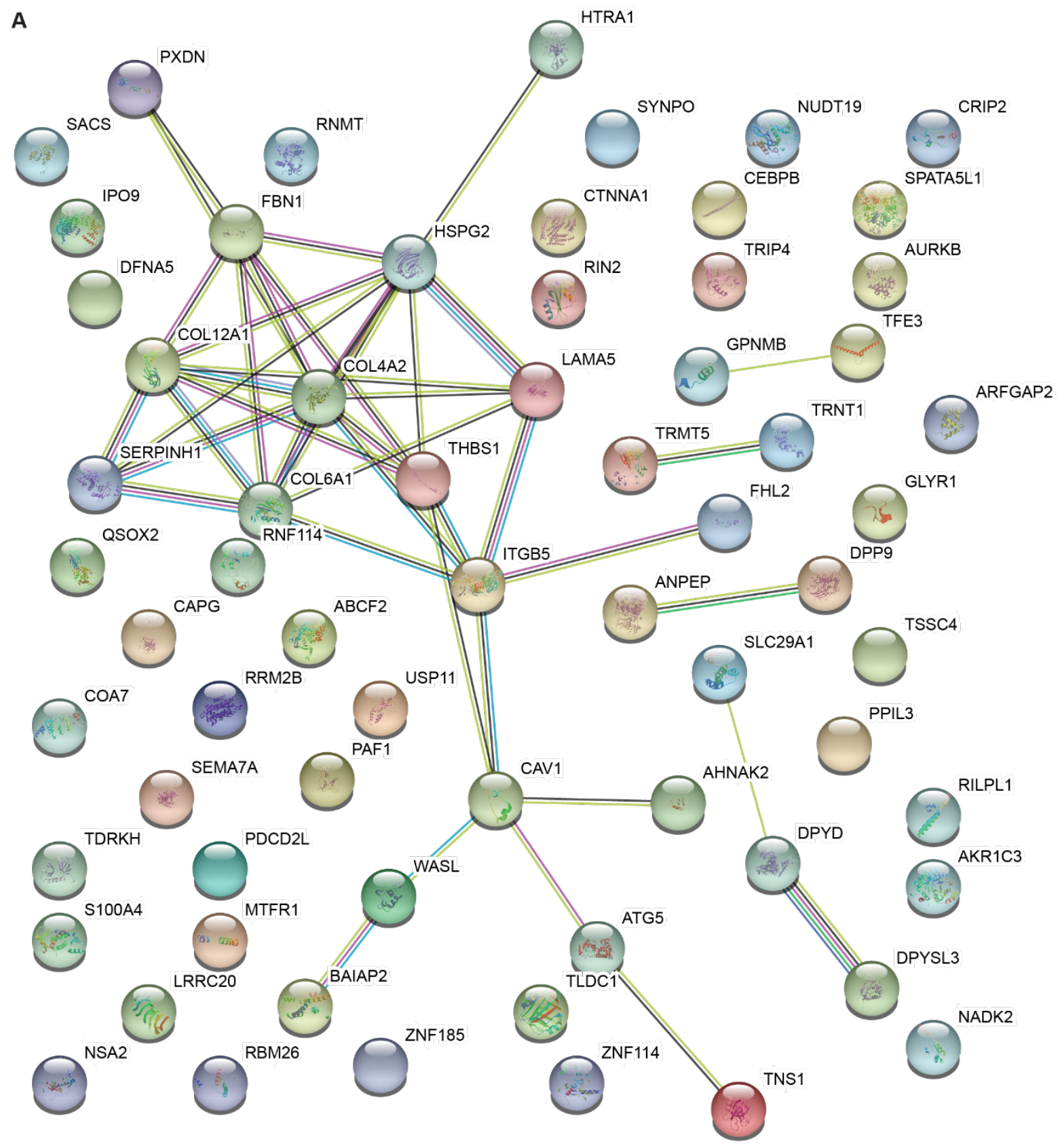


B

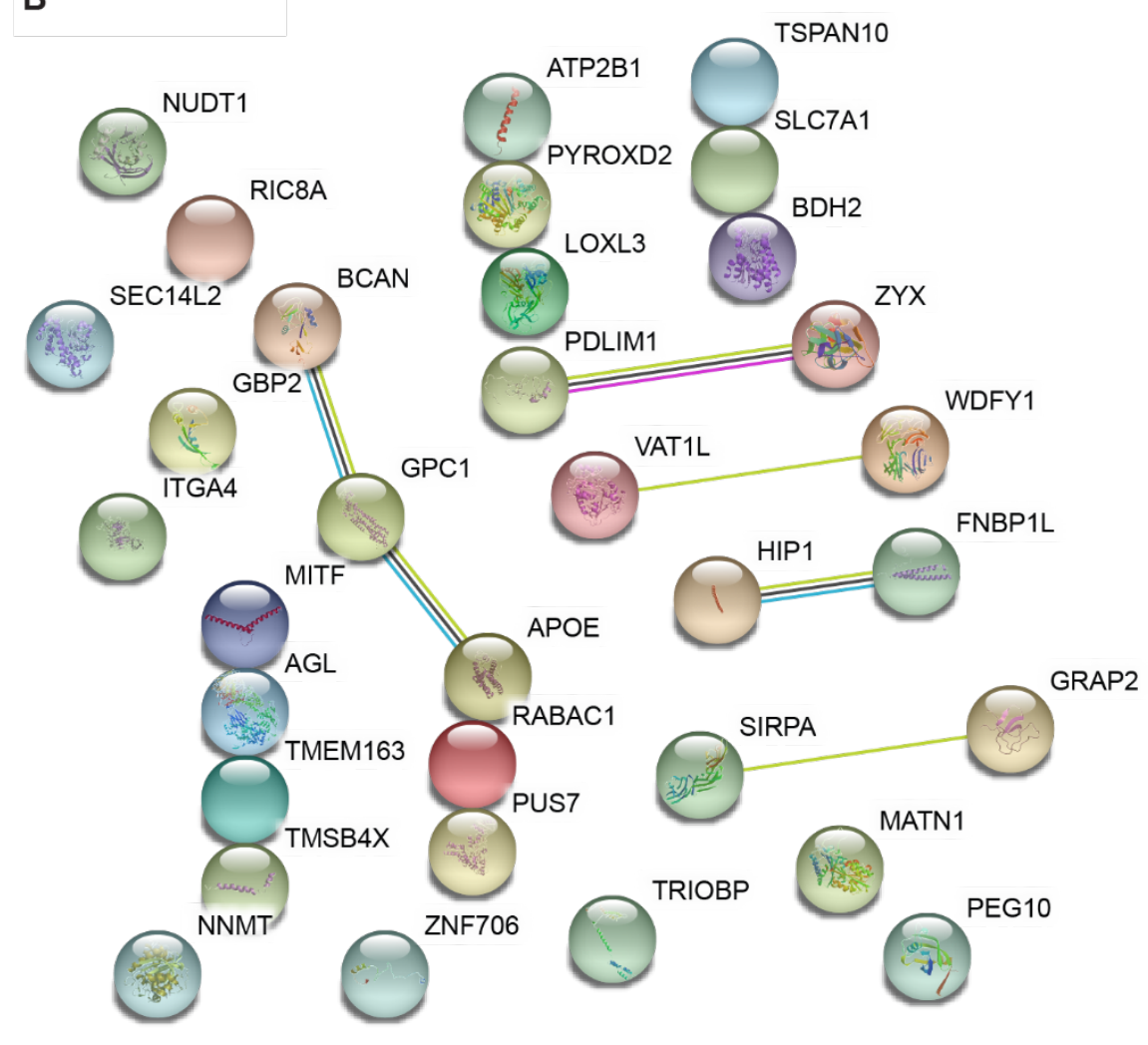

Figure S5: STRING generated network of proteomics identified hits. (A) C8161 ${ }^{\mathrm{MITF}-\mathrm{OE}}$ vS $\mathrm{C} 8161^{\mathrm{EV}}$. (B) WM164 ${ }^{\mathrm{MITF}-\mathrm{KD}}$ vs WM164 ${ }^{\mathrm{EV}}$. Network nodes represent proteins, their color is specific to each protein and non-empty nodes indicate that some 3D structure is known or predicted for that protein. Edges represent protein-protein associations, known interactions in cyan (from curated databases) and magenta (experimentally determined), predicted interactions in green (gene neighbourhood), red (gene fusions) and blue (gene co-occurrence) and other types of interactions in yellow (text mining), black (co-expression) and violet (protein homology). 

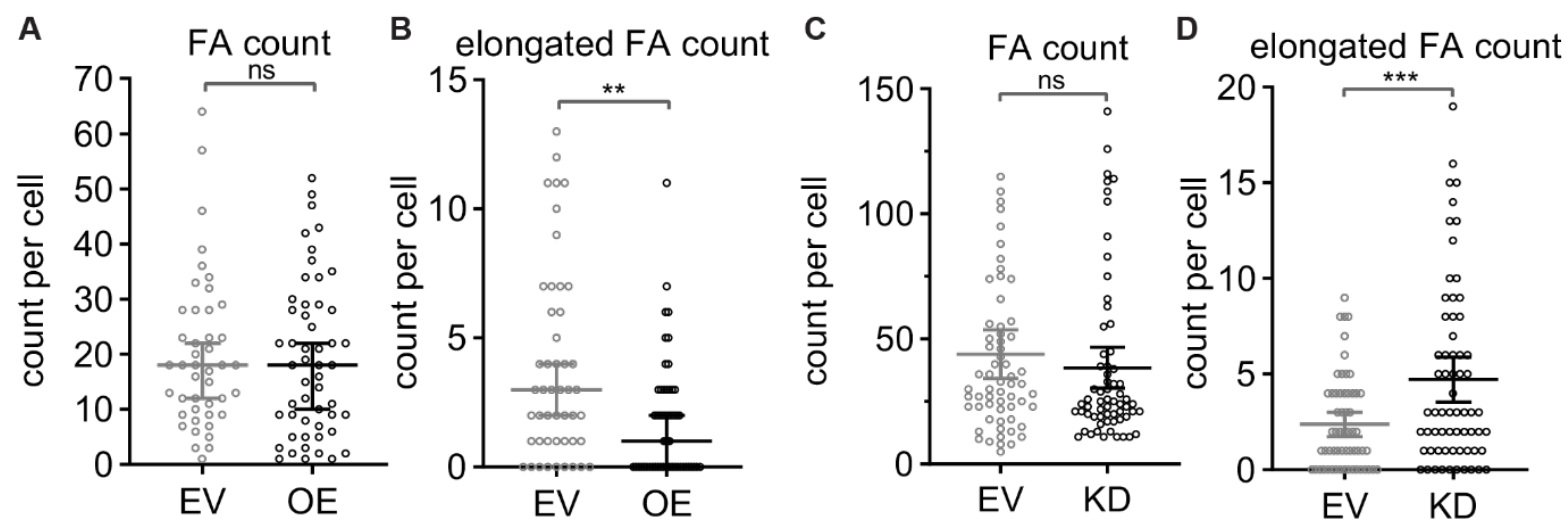

Figure S6: Count of focal adhesions. $\mathrm{C} 8161^{\mathrm{EV}}, \mathrm{C} 8161^{\mathrm{MITF}-\mathrm{OE}}, \mathrm{WM} 164^{\mathrm{EV}}$ and WM164 ${ }^{\mathrm{MITF}-\mathrm{KD}}$ cells were stained with an antibody against pFAK-Y397 and focal adhesions counted using CellProfiler software (A and C) and elongated focal adhesions counted manually (B and D). Graph shows number of adhesions per cells (each circle represents a cell). Scatter dot plot of data median with $95 \% \mathrm{CI}$; each dot represents a cell; $\mathrm{n}>44$ cells from three independent experiments; analysis: Student t-test, n.s. $\mathrm{p} \geq 0.05$. 